\title{
Nrf2/ARE Pathway Modulation by Dietary Energy Regulation in Neurological Disorders
}

\author{
Andrea Rodrigues Vasconcelos ${ }^{1 \dagger}$, Nilton Barreto dos Santos ${ }^{2 \dagger}$, Cristoforo Scavone ${ }^{1 *}$ \\ and Carolina Demarchi Munhoz ${ }^{2}$
}

'Laboratory of Molecular Neuropharmacology, Department of Pharmacology, Institute of Biomedical Science, University of São Paulo, São Paulo, Brazil, ${ }^{2}$ Laboratory of Neuroendocrinopharmacology and Immunomodulation, Department of Pharmacology, Institute of Biomedical Science, University of São Paulo, São Paulo, Brazil

\section{OPEN ACCESS}

Edited by:

Javier Egea,

Instituto de Investigación Sanitaria del Hospital Universitario de La Princesa,

Spain

Reviewed by: Giustino Orlando, Università degli Studi "G. d'Annunzio"

Chieti - Pescara, Italy Francesca Peruzzi,

LSU Health Sciences Center New

Orleans, United States

*Correspondence:

Cristoforo Scavone cristoforoscavone@gmail.com; cristoforo.scavone@gmail.com

${ }^{\dagger}$ These authors have contributed equally to this work

Specialty section:

This article was submitted to Inflammation Pharmacology,

a section of the journal

Frontiers in Pharmacology

Received: 02 October 2018

Accepted: 14 January 2019

Published: 04 February 2019

Citation:

Vasconcelos $A R$, dos Santos NB, Scavone C and Munhoz CD (2019) Nrf2/ARE Pathway Modulation by Dietary Energy Regulation

in Neurological Disorders.

Front. Pharmacol. 10:33.

doi: 10.3389/fphar.2019.00033
Nuclear factor erythroid 2-related factor 2 (Nrf2) regulates the expression of an array of enzymes with important detoxifying and antioxidant functions. Current findings support the role of high levels of oxidative stress in the pathogenesis of neurological disorders. Given the central role played by Nrf2 in counteracting oxidative damage, a number of studies have targeted the modulation of this transcription factor in order to confer neuroprotection. Nrf2 activity is tightly regulated by oxidative stress and energy-based stimuli. Thus, many dietary interventions based on energy intake regulation, such as dietary energy restriction (DER) or high-fat diet (HFD), modulate Nrf2 with consequences for a variety of cellular processes that affect brain health. DER, by either restricting calorie intake or meal frequency, activates Nrf2 thereby triggering its protective effects, whilst HFD inhibit this pathway, thereby exacerbating oxidative stress. Consequently, DER protocols can be valuable strategies in the management of central nervous system (CNS) disorders. Herein, we review current knowledge of the role of Nrf2 signaling in neurological diseases, namely Alzheimer's disease, Parkinson's disease, multiple sclerosis and cerebral ischemia, as well as the potential of energy intake regulation in the management of Nrf2 signaling.

\footnotetext{
Keywords: Nrf2, dietary energy restriction, high-fat diet, aging, Alzheimer's disease, Parkinson's disease, multiple sclerosis, cerebral ischemia
}

\section{INTRODUCTION}

It is widely recognized that oxidative stress plays a key role in CNS physiology and pathophysiology (Patel, 2016). Free radicals are constantly produced and are required at physiological levels for signaling and plasticity in the healthy brain. Conversely, their accumulation due to impaired cellular antioxidant defenses or excessive production that exceeds the cell's antioxidant capability can result

Abbreviations: 6-OHDA, 6-hydroxydopamine; $\mathrm{A} \beta$, Amyloid $\beta$; $\mathrm{AD}$, Alzheimer's disease; ARE, antioxidant response element; BBB, blood-brain barrier; BMI, body mass index; CAT, catalase; CNS, central nervous system; $\mathrm{CR}$, calorie restriction; DAMPS, damage-associated molecular patterns; DCs, dendritic cells; DER, dietary energy restriction; EAE, experimental autoimmune encephalomyelitis; GPx, glutathione peroxidase; GR, glutathione reductase; GST, glutathione S-transferase; HFD, high-fat diet; HO-1, heme oxygenase 1; IF, intermittent fasting; KEAP1, Kelch-like ECH associated protein 1; $\mathrm{MCA}$, middle cerebral artery; MCAO, middle cerebral artery occlusion; MnSOD, manganese superoxide dismutase; MPTP, methyl-4-phenyl-1, 2, 5, 6-tetrahydropyridine; MS, multiple sclerosis; NQO1, NADPH quinine oxidoreductase 1; Nrf2, Nuclear factor erythroid 2-related factor 2; OGDR, oxygen-glucose deprivation/reoxygenation; OPCs, oligodendrocytes and oligodendrocytes precursor cells; PD, Parkinson's disease; ROS, reactive oxygen species; RRMS, relapsing-remitting multiple sclerosis; SN, substantia nigra; SOD, superoxide dismutase; SPMS, secondary progressive multiple sclerosis; T2D, type 2 diabetes; tMCAO, transient middle cerebral artery occlusion; VEGF, vascular endothelial growth factor. 
in neurotoxicity and cell death, which if continued will ultimately lead to pathological processes (Cai et al., 2011). For this reason, oxidative stress has been extensively studied as a therapeutic target to treat brain diseases (Patel, 2016).

It is important to note that the brain can be highly susceptible to oxidative damage, due, in part, to its elevated oxygen demand, the presence of high amounts of polyunsaturated fatty acids that are easily targeted by free radicals, and lower levels of antioxidant enzymes compared to other organs (Ahmad et al., 2017; Mecocci et al., 2018). Some stable products of lipid peroxidation in the CNS are substantial oxidative stress biomarkers largely used in studies involving neurological and neurodegenerative disorders. These oxidation products include isoprostanes and neuroprostanes, derived from the non-enzymatic oxidation of arachidonic acid and decosahexanoic acid, respectively (Reed, 2011).

Aging leads to a gradual increase in brain oxidative stress, which is accompanied by reduced antioxidant defenses and lower levels of neurogenesis (Uttara et al., 2009). Aging is the main risk factor for neurodegenerative disorders (Niccoli and Partridge, 2012), which accounts for $12 \%$ of total deaths worldwide (World Health Organization [WHO], 2011; Chen et al., 2016b). Both acute and chronic inflammatory processes reciprocally interact with oxidative stress, with these factors being important to the etiology and course of a wide array of neurological conditions, such as $\mathrm{AD}, \mathrm{PD}, \mathrm{MS}$, and stroke, as well as to the process of aging per se (Sandberg et al., 2014).

Aging is also associated to a progressive reduction in Nrf2 activity (Cuadrado, 2016). Interestingly, long-lived animal species have higher Nrf2 signaling levels, highlighting the importance of Nrf2 protection against aging and aging-related diseases (Bruns et al., 2015). Nrf2 is pivotal in the regulation of cellular redox status, modulating the expression of more than 200 downstream genes encoding Phase II response enzymes during oxidative challenge, including HO-1, GST, CAT, SOD, and NQO1 (Nguyen et al., 2009; Sun et al., 2017). The phase II response in an evolutionary conserved adaption to a broad range of stressors and is intimately linked to the organism's antioxidant defenses, detoxification, and cellular resilience (Hine and Mitchell, 2012). A broad array of published data show that the upregulation of Nrf2 target genes in the CNS can render neurons more resistant to excitotoxic and oxidative insults (Chen et al., 2000; Satoh et al., 2006; Giordano et al., 2007; Tanito et al., 2007; Lim et al., 2008). Nrf2 not only modulates antioxidant defense genes, but also genes that have autophagic and anti-inflammatory properties as well as glucose and lipid metabolism effects (Bruns et al., 2015; Tebay et al., 2015). Nrf2 activation leads to its translocation to the cell nucleus where it triggers the expression of target genes that contain the ARE DNA regulatory sequence in their promoter region (Jaiswal, 2004). The Nrf2/ARE pathway is modulated by the KEAP1. In basal conditions, this protein acts as a Nrf2 repressor, binding to Nrf2 and maintaining it in the cell cytoplasm (Satoh et al., 2006). This regulatory protein also directs Nrf2 to ubiquitination and degradation by proteasomes, thereby limiting its basal cellular levels (Sun et al., 2017) (Figure 1).

Many dietary interventions modulate Nrf2. DER and high energy consumption are two of the most studied strategies for energy status regulation, and both act to modulate tNrf2 activity. DER increases Nrf2 activity, in contrast to high energy consumption. DER, induced by chronically or intermittently restricted calorie consumption, subjects neurons to an energetic stress that triggers the Nrf2/ARE pathway and thereby induces many beneficial effects on health and longevity, including the prevention of neurological diseases (Mattson, 2012). In contrast, a plethora of animal and human studies show that a HFD, and associated obesity, enhance inflammation and oxidative stress, resulting in a raised overall mortality and higher incidence of many neurological disorders (Dorrance et al., 2014; Michel, 2016; Mazon et al., 2017; Alfredsson and Olsson, 2018) (Figure 2). This chapter focuses on the Nrf2/ARE pathway regulation by dietary interventions and its protective role in the CNS against metabolic, excitotoxic, and oxidative insults, with relevance to $\mathrm{AD}, \mathrm{PD}, \mathrm{MS}$, and cerebral ischemia.

\section{Nrf2/ARE PATHWAY AND NEUROLOGICAL DISEASES}

Both in vitro and in vivo neurodegenerative models have demonstrated that Nrf2 activation promotes neuroprotective effects (Calkins et al., 2009). However, as noted above, Nrf2 activity declines with age, consequently decreasing the protection afforded by antioxidant enzymes activity. Such Nrf2/ARE signaling impairment renders the organism and the brain more susceptible to oxidative injury, abnormal protein aggregation and neurodegeneration (Itoh et al., 1997; Suh et al., 2004; Shih and Yen, 2007; Morrison et al., 2010; Safdar et al., 2010; Cuadrado, 2016). A number of studies have underscored the importance of the Nrf2/ARE pathway to the pathogenesis and treatment of neurological disorders, including $\mathrm{PD}, \mathrm{AD}, \mathrm{MS}$, and cerebral ischemia, as described below.

\section{Alzheimer's Disease}

Alzheimer's disease is the leading cause of senile dementia, characterized by progressive cognitive impairment and memory loss. In the United States, it is estimated that 5.7 million people have $\mathrm{AD}$ in 2018 and this number is predicted to reach 14 million by 2050, due to rises in longevity (Alzheimer's Association, 2018). Classically, $\mathrm{AD}$ has been thought to be driven by the accumulation of amyloid- $\beta$ peptide $(A \beta)$ aggregates and neurofibrillary tangles composed of hyperphosphorylated tau proteins (Arriagada et al., 1992; Selkoe, 1994). However, there is a growing appreciation of a role for other processes in AD etiology and course, including changes in oxidative stress (Mecocci et al., 2018). Oxidative stress markers have long been shown to be increased in AD. Patients with mild cognitive impairment, often a forerunner of $\mathrm{AD}$, also show raised levels of oxidative damage and reduced antioxidant defenses, in comparison to healthy controls (Migliore et al., 2005; Bermejo et al., 2008; Mangialasche et al., 2009; Padurariu et al., 2010). Markers of oxidative stress are all increased in AD, including 4-hydroxynonenal (a product of lipid peroxidation) (Bradley et al., 2012; Di Domenico et al., 2017), and protein nitration and carbonylation (Perluigi et al., 2009; 


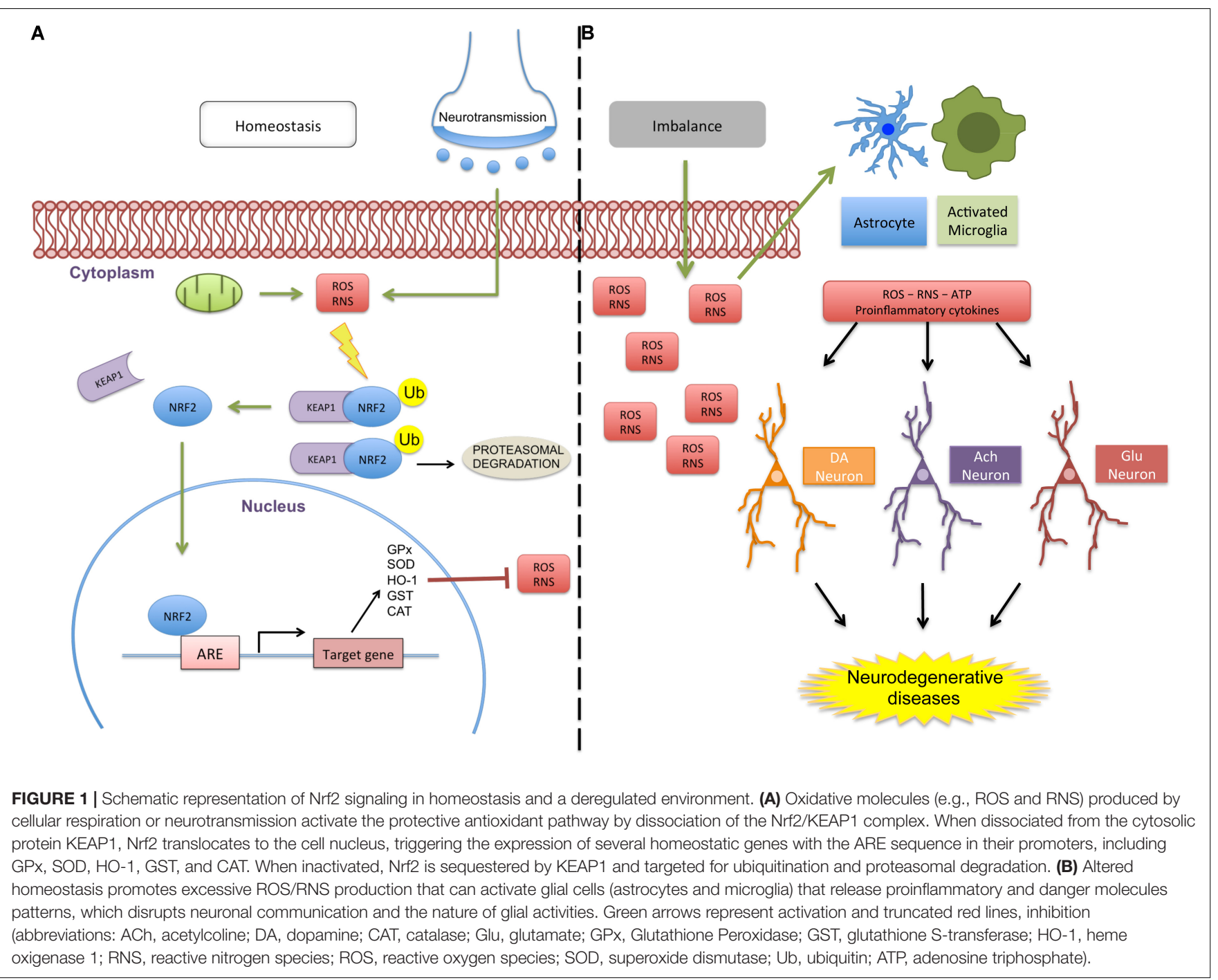

Aluise et al., 2011). These changes are often accompanied by a decline in antioxidant defenses, which contributes to such heightened oxidative stress in AD patients (Kim et al., 2006).

Nrf2 levels are decreased in the AD brain (Kanninen et al., 2008). This is supported by data from preclinical models of AD, which indicate reduced brain Nrf2 expression levels (Carvalho et al., 2015; Liu et al., 2016; Manczak et al., 2018), with Nrf2 activation mitigating neuronal apoptosis and spatial memory impairment (Dong F. et al., 2017). Several in vivo and in vitro studies also show that the activation of $\mathrm{Nrf} 2 / \mathrm{HO}-1$ signaling cascade by flavonoids and microRNA-302 affords protection against neuronal toxicity induced by $\mathrm{A} \beta$ (Zou et al., 2013; Kwon et al., 2015; Li H.H. et al., 2016; Wang et al., 2016). Moreover, Nrf2 knockout mice have an impaired clearance of phosphorylated tau by autophagy, contributing to heightened tau aggregation and accumulation in the brain, a well-known hallmark of $\mathrm{AD}$ (Jo et al., 2014). In an $\mathrm{AD}$ murine model, Nrf2 deletion also results in impaired autophagy, and therefore a decrease in the ability of a cell to clear debris (Joshi et al., 2015). These findings highlight the importance of Nrf2 in AD pathophysiology as well as indicating its potential therapeutic utility in $\mathrm{AD}$.

In contrast, Raina et al. (1999) reported increased levels of NQO1 in AD human brains, suggesting Nrf2 activation. Similarly, three common Nrf2 target genes (p62, HO-1, and GCLM) are upregulated in AD brains (Tanji et al., 2013). Such contrasting results may be due to differential effects on Nrf2 levels at different $\mathrm{AD}$ stages, perhaps indicative of an upregulation of antioxidant defenses to counteract oxidative stress in early $\mathrm{AD}$ stages, whilst the loss of endogenous antioxidants and Nrf2/ARE pathway activity may be more evident in latter phases of the disease (Sun et al., 2017).

\section{Parkinson's Disease}

After $\mathrm{AD}, \mathrm{PD}$ is the second most prevalent neurodegenerative disease. PD is typically characterized by progressive movement disorders (rigidity, resting tremor, postural instability, hypokinesia, and bradykinesia) as well as by variable degrees of cognitive dysfunction and dementia (Goris et al., 2007; Tufekci et al., 2011). A number of different brain regions show 
atrophy in PD, with classic PD symptomatology mediated by the loss of dopamine neurons in the SN. An accumulation of $\alpha$-synuclein protein is common, in association with proteasome and mitochondria impairment (Mattson, 2012).

As with $\mathrm{AD}$, the etiology of $\mathrm{PD}$ still awaits clarification, with a number of studies indicating that oxidative stress is an important contributor to PD pathogenesis and course, including via increased membrane lipid peroxidation and protein damage (Duan and Mattson, 1999; Jenner, 2007; Cuadrado et al., 2009). Sources of oxidative stress in PD brain include chronic neuroinflammation, the metabolism of dopamine producing cytotoxic ROS, and mitochondrial impairment (Blesa et al., 2015). Nrf2 is an emerging target to counteract PD-related neuronal cell death, given its regulation of a plethora of cytoprotective genes with anti-inflammatory and antioxidant properties, as well as its role in optimizing mitochondria biogenesis (Tufekci et al., 2011). Data from human post-mortem PD brains and Nrf2 knockout mice indicate an association between Nrf2/ARE pathway dysfunction and PD pathogenesis (Tufekci et al., 2011). Such data shows that Nrf2 deficiency increases the sensitivity of mice to PD neurotoxins (Jakel et al., 2007; Chen et al., 2009; Colton, 2009), whereas the induction of this transcription factor in astrocytes exerts a protective effect against brain damage in the 6-OHDA model of PD (Jakel et al., 2007). In post-mortem brains of PD patients, the proteins $\mathrm{p} 62$ and NQO1 were partially sequestered in Lewy bodies, indicating a compromised neuroprotective capacity of Nrf2 (Lastres-Becker et al., 2016). In the same study, Nrf2 pharmacological activation by dimethyl fumarate in a murine PD model protected SN neurons against $\alpha$-synuclein toxicity, an effect not evident in Nrf2-knockout mice (Lastres-Becker et al., 2016). Jazwa et al. (2011) also showed that Nrf2 activation upregulates brain HO1 and NQO1 expression and prevents SN neuronal death as induced by MPTP, a neurotoxin PD model. Furthermore, the link between Nrf2 and PD is also supported by studies showing that antiparkinsonian drugs (e.g., apomorphine, deprenyl, and bromocriptine) can activate the Nrf2/ARE pathway and Nrf2dependent gene expression, preventing cell oxidative damage and neurodegeneration (Hara et al., 2006; Nakaso et al., 2006; Lim et al., 2008; Kabel et al., 2018).

In human PD brain tissue, Ramsey et al. (2007) showed that hippocampal neurons and glia from CA1 region had lower nuclear Nrf2 when compared to age-matched healthy controls. In contrast, SN neurons of PD patients had higher Nrf2 nuclear localization, indicative of Nrf2 activation, although not sufficient to counteract neurodegeneration in these individuals (Ramsey et al., 2007). Similarly, Nrf2-dependent gene expression is decreased in the striatum but increased in the SN of the MPTP model (Ramsey et al., 2007). A recent study also reported increased Nrf2 activation in SN of mice treated with MPTP, prior to the onset of neurodegeneration (Rizzi et al., 2018).

Further research is required to clarify why the increased Nrf2dependent gene expression and nuclear translocation in the SN reported in the aforementioned studies is incapable of protecting neurons against oxidative damage. A number of studies indicate a crucial role for Nrf2 activation in glial cells (Jakel et al., 2007; Chen et al., 2009), suggesting that Nrf2 may need to be activated

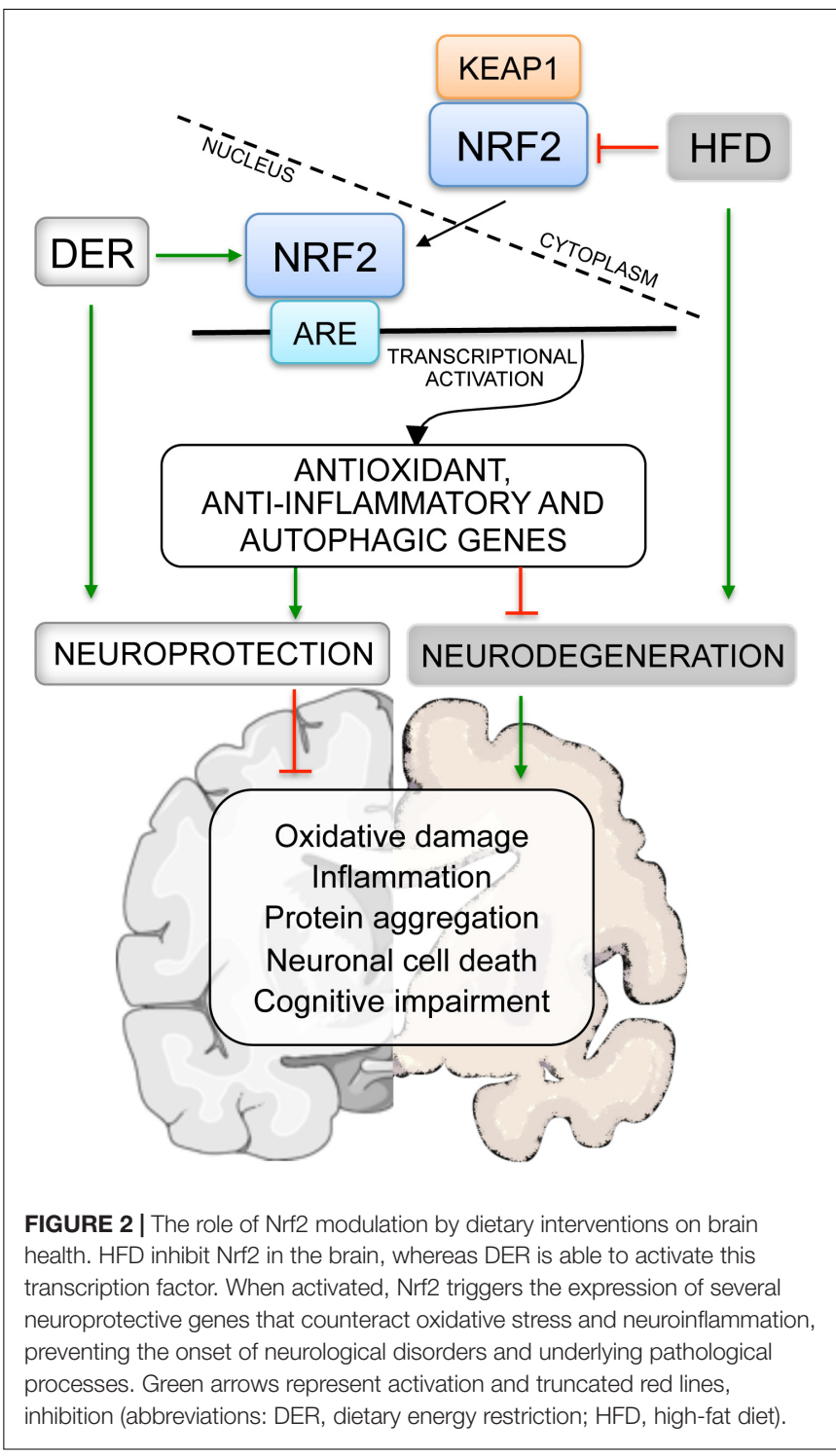

in glia in order to exert its protective effects in PD and PD models. Ramsey study did not report glial Nrf2 nuclear translocation in the SN of PD brains (Ramsey et al., 2007) and in vitro studies indicate that neuronal Nrf2 activation, even in the absence of glia, induces neuroprotection against oxidative damage triggered by parkinsonism-inducing neurotoxins (Lee et al., 2003; Cao et al., 2005; Hara et al., 2006; Jakel et al., 2007; Wruck et al., 2007; Hwang and Jeong, 2008; MacKenzie et al., 2008; Satoh et al., 2009; Niso-Santano et al., 2010). Overall, such work indicates that increased Nrf2 activity in both glia and neurons is important to neuronal survival in PD (Tufekci et al., 2011).

\section{Cerebral Ischemia}

Cerebrovascular diseases are the second leading cause of death worldwide. Without intervention, the cases of deaths worldwide are estimated to increase from 6.5 million in 2015 to $7-8$ million in 2030 (Strong et al., 2007). Ischemic stroke is characterized by decreased blood flow in the brain, causing injury to brain 
tissues and impairing normal neurological functioning (Jauch et al., 2013; Ding et al., 2017).

The reduced delivery of nutrients and oxygen after stroke decreases tissue $\mathrm{pH}$, resulting in impairment of the mitochondrial electron transport chain activity and subsequent diminished ATP production. Subsequently, a cascade of events follows that culminates in raised intracellular $\mathrm{Na}^{+}, \mathrm{Ca}^{2+}, \mathrm{Cl}^{-}$concentrations, and $\mathrm{K}^{+}$efflux. The neuronal cations increase leads to excessive depolarization and the release of excitatory neurotransmitters, such as glutamate, causing excitotoxicity and triggering oxidative and cell death pathways (Nicholls, 2009).

Increased oxidative stress is evident in stroke. Murine models, subjected to ischemia-reperfusion, show a high concentration of superoxide and peroxynitrite, as well as metalloproteinase- 9 production and BBB breakdown (Gursoy-Ozdemir et al., 2004). The anti-apoptotic and anti-oxidative effects of the Nrf2 signaling pathway in stroke have been noted. Nrf2 activators are able to reduce oxidative stress and exert protective roles in models of stroke (Alfieri et al., 2011; Yang et al., 2018). Astrocyte Nrf2 activation is important to the release of antioxidants, such as glutathione, which protect neurons from free radicals produced during ischemia (Alfieri et al., 2011).

Recent work shows Nrf2 to induce angiogenesis via HO-1 (Ding et al., 2014) and VEGF signaling (Huang Y. et al., 2018), which is supported by the work of Bai and coworkers who showed that epigallocatechin-3-gallate, the major effective polyphenol in green tea, promotes angiogenesis and decreases oxidative stress via MAPK/Nrf2/VEGF activation, following tMCAO (Bai et al., 2017; Li L. et al., 2016).

In addition to antioxidant effects, Nrf2/ARE activation can afford protection against the neuroinflammation evident following ischemia. In the ischemic brain, ROS, as with DAMPS, can activate the NLRP3 inflammasome, thereby converting prointerleukin (IL)-18 and pro-IL-1 $\beta$ into mature IL-18 and IL-1 $\beta$ forms, which are then released (Inoue et al., 2012). Glial cells are important drivers of neuroinflammation and NLRP3 activation (Frank et al., 2007; Gavillet et al., 2008). Xu et al. (2018) showed that the Nrf2/ARE pathway protects against the oxidative stress-induced NLRP3 activation in the BV2 microglial cell line exposed to OGDR. Moreover, neonatal rats treated with LPS $24 \mathrm{~h}$ prior to hypoxia-ischemia, were protected against neuropathological effects, whereas LPS administration $72 \mathrm{~h}$ before hypoxia-ischemia increased brain damage, which was prevented by treatment with $\mathrm{N}$-acetylcysteine, a glutathione precursor (Wang et al., 2007). Such data support the idea that Nrf2 upregulation varies according to the time of ischemia exposure, as well as cell type (glial cells or neurons) and antioxidant reserve. Such data suggests complex effects, although it is clear that Nrf2-related pathways are important molecular targets for pharmacologic intervention in the management of ischemic stroke.

\section{Multiple Sclerosis}

Multiple sclerosis is the most frequent chronic neuroinflammatory disease of the CNS, characterized by demyelination, as well as focal inflammatory lesions in the brain and spinal cord, which culminates in axonal damage
(Lassmann, 2011b). MS is also associated with gray matter synaptic loss and decreased neurogenesis, which contributes to cognitive impairment. MS clinical symptoms include sensory or motor impairment, fatigue, ataxia, and spasticity, as well as cognitive impairment (Chiaravalloti and DeLuca, 2008; Lublin et al., 2014). EAE is the most common experimental model of MS (Simmons et al., 2013). Activated macrophages and microglial cells can produce an array of neurotoxic factors, including proteases, nitric oxide, and ROS, with this being evident in both MS and the EAE model (Glass et al., 2010). Generation of ROS and other free radicals by macrophages is involved in demyelination and axonal damage in EAE. Evidence of lipid peroxidation, as a consequence of oxidative stress, can be detected in the exhaled breath samples of MS patients. Additional studies have shown decreased levels of antioxidant enzymes in blood and cerebrospinal fluid of MS patients (Lassmann, 2011a,b, 2014; Witte et al., 2014). Such data highlights the importance of heightened levels of immune-inflammatory activity and oxidative stress in MS.

Therapeutic strategies in the treatment of MS have primarily focused on dampening the heightened immune-inflammatory activity that is present, including by the use of: imunossupressors, such as synthetic glucocorticoids (e.g., dexamethasone, prednisone, and methylprednisone); monoclonal antibodies (Natalizumab); inhibitors of cell egress from lymphoid organs (Fingolimod), modulators of pro- and anti-inflammatory cytokines (interferon-beta); and microglial inhibitors (acetate glatiramer). However, all of these treatments have shown limited efficacy. Antioxidant therapies have proved to have some utility when used as adjuvants in MS treatment, with endogenous Nrf2 being an important treatment target for the induction of endogenous antioxidants (Kappos et al., 2010; Lim et al., 2014).

Classical treatment in MS has emphasized the role of heightened immune-inflammatory processes. As noted above, such processes are intimately linked to alterations in redox regulation. There is now a growing appreciation of the role the oxidant/antioxidant balance in MS. A growing body of data indicates an important role for ROS in MS, including: a central role in MS lesion development and progression and an initial contribution to the BBB breakdown and leukocyte infiltration that is crucial in early phases of lesion formation in MS (Van der Goes et al., 2001; Schreibelt et al., 2006). ROS can cause oxidative injury in CNS cells, including during demyelination, oligodendrocyte injury, and axonal degeneration. OPCs are highly vulnerable to oxidative injury due to their low levels of endogenous antioxidant enzymes and the relatively high levels of polyunsaturated fatty acids in the myelin sheets, which are more susceptible to lipid peroxidation (Juurlink et al., 1998; French et al., 2009). Furthermore, free radicals are able to impair the maturation of OPCs into myelin-forming mature cells by modulating the genes driving maturation and differentiation.

Antioxidant molecules and oxidative stress are upregulated in active brain lesions in MS patients, but not to a sufficient level to counteract the oxidative stress evident in MS brain tissue. NADPH oxidase subunits are strongly upregulated in the macrophages and microglia in active MS lesions, suggesting 
an important role for heightened ROS, including as mediated by an oxidative burst, in the pathophysiology of active lesions. Contributing to such damage are increased expression of inducible nitric oxide synthase (Bo et al., 1994; De Groot et al., 1997; Liu et al., 2001) and myeloperoxidase (Marik et al., 2007; Chen et al., 2008; Gray et al., 2008a,b; Wang et al., 2016) that are evident in the brains of MS patients.

Although a number of different cell types, such as macrophages, can have an antigen presenting capacity, DCs are the body's major antigen presenting cells. There is growing body of data indicating that $\mathrm{Nrf} 2$ may regulate the differentiation and function of macrophages and DCs, and therefore in antigen presentation and the regulation of adaptive immune response. In fact, Nrf2 deficiency modifies the phenotype and function of DCs by increasing the expression of co-stimulatory molecules and consequently the antigen-specific $\mathrm{T}$ cell reactivity (Al-Huseini et al., 2013). Some of these Nrf2 effects may be mediated via alterations in mitochondrial functioning, as indicated above, including in the mitochondrial regulation of immune cell responses.

$\mathrm{Nrf} 2$ is strongly upregulated in active MS lesions, with the expression of Nrf2-responsive genes being predominantly found in areas of initial myelin destruction (Licht-Mayer et al., 2015). Analyses of MS inflammatory lesions showed upregulation of Nrf2 and its downstream antioxidant enzymes, HO-1 and NQO1. In support of the importance of such Nrf2-mediated changes, experimental studies in Nrf2-deficient EAE mice show an increase in disease signals and peripheral cell infiltration (Lim et al., 2014). Accordingly, Johnson et al. (2010) showed that the absence of Nrf2 exacerbates the development of EAE. Part of the effects associated with $\mathrm{Nrf} 2$ deficiency may be related to the reduced levels of HO-1. Indeed, mice with a myeloid-specific HO-1 deficiency exhibit a higher incidence of lesions, accompanied by activation of antigen-presenting cells and the infiltration of the pro-inflammatory $t$ helper (Th)17 cells and myelin-specific T cells (Tzima et al., 2009). Knockdown of KEAP1 (Kobayashi et al., 2016) or treatment with a wide range of small molecules that activate Nrf2 (Buendia et al., 2016) inhibits the development and severity of EAE.

\section{ROLE OF Nrf2/ARE PATHWAY MODULATION BY DIETARY INTERVENTIONS IN NEUROLOGICAL DISEASES}

A growing literature shows Nrf2 to regulate the expression of genes that reduce gluconeogenesis and lipogenesis, whilst also increasing fatty acids $\beta$-oxidation and mitochondria activity. Such data indicates that Nrf2 activity intimately interacts with cellular nutritional and energetic status (Holmstrom et al., 2013; Ludtmann et al., 2014; Tebay et al., 2015). The multiple molecular pathways that may underpin such interactions have been reviewed previously (Tebay et al., 2015). The present article reviews the current knowledge of dietary interventions, namely
DER and HDF, on Nrf2 and the relevance of this to neurological disorders.

\section{Dietary Energy Restriction}

Dietary energy restriction, the decrease of food intake without malnutrition, is the most powerful intervention known to delay aging processes and extend lifespan (Pearson et al., 2008; Hine and Mitchell, 2012). Several studies have comprehensively highlighted the beneficial effects of DER on cognitive function, metabolic health, and longevity, which have been especially associated with the two main DER protocols: caloric restriction (CR) and IF (Horne et al., 2015; Vasconcelos et al., 2018). In $\mathrm{CR}$ protocol, calorie consumption is chronically decreased in $20-40 \%$ of the ad libitum intake, whilst IF involves a restriction in the frequency of food intake, giving periods of free food intake coupled to fasting periods. These protocols were shown to extend life- and health-span and to counteract numerous age-related diseases. The vulnerability of the CNS to age progression is frequently expressed in neurological disorders, such as AD, PD, and stroke (Martin et al., 2006; Logsdon et al., 2017).

Dietary energy restriction, as a mild stress of energy restriction to the organism, is considered a hormetic stimulus, which is defined as a low dose stressor that induces adaptive responses able to improve resistance to more severe stressors and diseases. Within this context, the energetic challenge to the brain induced by DER triggers beneficial outcomes, including neurogenesis, synapses strengthening, and new synapse formation (Calabrese et al., 2010; Hine and Mitchell, 2012; Horne et al., 2015). Molecularly, DER induces the activation of protective transcription factors, such as Nrf2, that activate the expression of Phase II detoxifying enzymes, thereby increasing neuronal resistance to oxidative stress and death, and hence lowering the risk of neurodegenerative disorders. DER, especially IF, upregulates genes encoding the antioxidant enzymes that are modulated by Nrf2, including GPx, SOD2, and HO-1 (Hine and Mitchell, 2012; Mattson, 2012).

Some of the benefits of CR protocol are associated with Nrf2/ARE pathway activation (Pearson et al., 2008; MartinMontalvo et al., 2011; Bruns et al., 2015). One of the proposed mechanisms of DER utility is via a transient ROS increase to hormetic levels that may activate Nrf2 (Hine and Mitchell, 2012). For instance, fasting, and its consequential effects on insulin levels, results in a small, transient increase in oxidative stress, triggering activation of the Nrf2/ARE pathway and the upregulation of its target genes (Kim and Novak, 2007).

Various age-related diseases, including $\mathrm{AD}$ and $\mathrm{PD}$, are linked to decreased Nrf2 activity and display symptom improvement after Nrf2 activation by DER (Hine and Mitchell, 2012). CR can counteract the age-related loss of cellular antioxidant defenses, partly by promoting the up-regulation of Nrf2/ARE-driven genes, including GST and NQO1, in a variety of body tissues and organs, including the liver and brain (Chen et al., 1994; Hyun et al., 2006). Furthermore, a recent study showed that $30 \% \mathrm{CR}$ for 12 weeks can prevent neurotoxicity, oxidative damage, and cognitive impairment induced by acrolein. Acrolein has been proposed to be involved in $\mathrm{AD}$ etiology, with the efficacy of $\mathrm{CR}$ 
mediated, at least partly, through the amelioration of acroleininduced depletion of hippocampal SOD levels, indicating a positive effect of this protocol on Nrf2 signaling (Huang Y.J. et al., 2018).

The age-induced Nrf2 dysfunction in BBB endothelial cells is also prevented by $\mathrm{CR}$, shedding light in the cerebrovascular protective effects of this DER protocol (Csiszar et al., 2014). Importantly, these age-dependent endothelial alterations are thought to play a role in both vascular cognitive impairment and AD (Gorelick et al., 2011; Zlokovic, 2011; Lin et al., 2013). Accordingly, numerous substances proposed as "DER mimetics" (i.e., compounds shown to promote the beneficial effects of DER in the absence of food intake restriction), such as curcumin, resveratrol, and quercetin (Ingram et al., 2006), have been shown to increase longevity and slow down the aging process, at least in part via Nrf2 activation (Balogun et al., 2003; Chen et al., 2005; Hsieh et al., 2006; Tanigawa et al., 2007; Calabrese et al., 2010).

Several studies in murine and primate models of PD have demonstrated that DER can protect dopaminergic neurons, decrease motor dysfunction, and alleviate PD symptoms (Duan and Mattson, 1999; Maswood et al., 2004; Qiu et al., 2012; Griffioen et al., 2013), even when the DER protocol is initiated after the induction of PD by MPTP (Holmer et al., 2005). Published data also indicate that energy consumption profoundly impacts the progression of AD (Mattson, 2012), with DER decreasing brain $A \beta$ accumulation in the APP transgenic murine model of AD (Patel et al., 2005; Wang et al., 2005) and aged primates (Qin et al., 2006). Furthermore, in a triple transgenic $\mathrm{AD}$ mice, both IF and CR protocols, when starting at 3 months of age (before symptoms onset), can counteract age-related cognitive impairment (Halagappa et al., 2007). Interestingly, in this study, CR, but not IF, reduced $A \beta$ deposition in the brain. The authors suggest that the IF mechanism of action may involve the prevention of $A \beta$-mediated negative effects on cognitive function.

Glutathione is an important reducing agent of the phase II antioxidant response. Many genes involved in glutathione metabolism are modulated by $\mathrm{Nrf} 2$, including glutathione synthesis genes (GCLM, GCLC), GST, GPx, and GR. Several studies have reported an age-related disruption of the glutathione antioxidant system in rodents and humans, which may result in increased susceptibility to PD and AD (Rao et al., 1990; Samiec et al., 1998; Cho et al., 2003; Suh et al., 2004; Kennedy et al., 2005; Ballatori et al., 2009; Hine and Mitchell, 2012). Cho et al. (2003) showed that CR in rodents is able to prevent the age-related decrease in the levels of glutathione and glutathionerelated enzyme activities. Furthermore, many studies showed that GST and GPx levels and activities can be augmented by both fasting and CR (Leakey et al., 1989; Cho et al., 2003; Pearson et al., 2008; Mitchell et al., 2010; Vazquez-Medina et al., 2011). In one of these studies, these effects were evident in mice subjected to $30 \%$ CR for 2-4 weeks or short periods of fasting, following ischemia reperfusion injury (Mitchell et al., 2010). Results from the CALERIE Trial of Human Caloric Restriction also showed that GPx activity is increased by $10-30 \%$ CR over 6 months in overweight individuals (Meydani et al., 2011).

NQO1 is another important endogenous antioxidant defense enzyme modulated by Nrf2. Altered expression of NQO1 is correlated with many pathologies, including AD and PD (LastresBecker, 2017; Chhetri et al., 2018). Long term DR can increase NQO1 expression, resulting in enhanced antioxidant defenses in the brain and liver of aged rats (De Cabo et al., 2004; Hyun et al., 2006). This effect was also observed in studies using DER mimetics (Zhu et al., 2005; Higgins et al., 2009; Son et al., 2010).

DER and its mimetics can also counteract damage following ischemia reperfusion injury (Go et al., 1988; Khan et al., 2006; Saleh et al., 2010; Peng et al., 2012). After experimental stroke in rodents, 70 days of DER leads to a substantial attenuation of cognitive dysfunction as well as increasing hippocampal cell survival (Roberge et al., 2008). These effects seem, in part, to involve the Nrf2-triggering effect of DER (Mattson, 2012). Fasting for up to 4 days or $30 \%$ CR for 2-4 weeks results in augmented HO-1 expression and attenuates ischemic damage of the brain, liver, and kidney in rodents (Go et al., 1988; Mitchell et al., 2010; Verweij et al., 2011). Moreover, in vivo or in vitro data shows that DER mimetics, such as curcumin and plumbagin, also increase HO-1 expression and render rodents more resistant to acute stressors and oxidative damage (Farombi et al., 2008; Son et al., 2010). In one of these studies, plumbagin pre-treatment in a murine model of focal ischemic stroke led to the attenuation of brain injury and neurological deficits. These effects were attributed to Nrf2/ARE activation, given that Nrf2 knockdown prevents such neuroprotective effects (Son et al., 2010).

Current MS treatments have poor efficacy, both for symptom relief and disease progression (Lublin et al., 2014). Genetic risk factors do not fully explain the development of MS, with a number of environmental factors, including infections, smoking, low vitamin $\mathrm{D}$ levels and obesity, associated with increased incidence of MS (Ascherio, 2013). A number of studies show childhood/young adulthood obesity to be a risk factor for MS (Munger et al., 2009; Hedstrom et al., 2012, 2014; Langer-Gould et al., 2013). The chronic inflammatory state that is evident in obesity can promote autoimmunity though adipokine production (Calder et al., 2011). The effects of diet on the gut microbiome is thought to contribute to this, via the regulation of pro- and anti-inflammatory responses that regulate DC activation, $\mathrm{MHC}$ II presentation, and $\mathrm{T}$ cell differentiation in the gut (Goto et al., 2014; Furusawa et al., 2015). The gut microbiome in both RRMS patients and EAE models is altered compared to healthy controls (Chen et al., 2016a; Jangi et al., 2016). Several dietary habits such as high salt intake or long chain fatty acid intake, have been recently recognized as environmental contributors to the pathogenesis of MS and EAE, by expanding TH1 and TH17 cells (Berer et al., 2011; Kleinewietfeld et al., 2013).

Chronic CR has a potent anti-inflammatory effect, protecting against EAE symptoms (Piccio et al., 2008; Meydani et al., 2016). In these studies, CR reduced inflammation, demyelination, and neurodegeneration ameliorating relapsing-remitting EAE in SJL mice and progressive EAE in C57BL/6 mice. CR lowers plasma IL- 6 concentration in the course of EAE accompanied by a decrease in leptin, suggesting CR-mediated alterations in the gut-brain axis and associated changes in gut-mediated inflammatory processes (Piccio et al., 2008). As leptin induces Th1 cell differentiation, such changes are likely to lower the levels of proinflammatory cytokine production (Matarese et al., 2005). 
Accordingly, MS patients showed an increased concentration of leptin in the serum and cerebrospinal fluid, associated with reduced levels of CD4 $(+) \mathrm{CD} 25+$ regulatory $\mathrm{T}$ cells and augmented INF- $\gamma$ release (Matarese et al., 2005).

Recent studies indicate that MS show characteristics of metabolic disease, with SPMS patients showing elevated peroxisomal metabolites (PlsEtn) and increased mitochondrial stress metabolites (VLCFA-PtdEtn), when compared to control patients (Senanayake et al., 2015). Furthermore, SPMS patients showed reduced seric anti-inflammatory hydroxylated longchain fatty acids called gastro-intestinal tract acids (GTAs), suggesting a diminished protection against MS-related inflammation. In addition, the oxidative stress-induced mitochondrial dysfunction in MS may provide biomarkers for the susceptibility to, and progression of, MS.

Importantly, although Nrf2/ARE signaling plays a critical role in cellular detoxification responses and prevention of age-related diseases, excessive Nrf2 activation has deleterious consequences. This is supported by studies showing KEAP1 knockout to be lethal in mice as a consequence of excessive constitutive Nrf2 activation (Wakabayashi et al., 2003), with Nrf2 overexpression (DeNicola et al., 2011; Lister et al., 2011) or mutation of KEAP2 (Zhang et al., 2010) promoting tumorigenesis. Consequently, pharmacological activation of Nrf2 may be dangerous, with the physiological activation of Nrf2 by DER likely to be a safer alternative.

\section{High Energy Consumption}

The Western lifestyle are frequently more sedate with greater levels of over-eating, characterizing a condition of chronic positive energy balance (Martin et al., 2009; Mattson, 2012). In contrast to DER, high-energy consumption is associated with many negative impacts on overall health and longevity, resulting in increased morbidity and mortality (Maffei et al., 1995; Caro et al., 1996; Herrmann et al., 2001). Consequently, being overweight or obesity has reached epidemic proportions, being now classed as the fifth largest cause of death worldwide (Razay et al., 2006; Procaccini et al., 2016). In fact, the World Health Organization estimated that the global burden of obesity and overweight was over 300 million and 1 billion of adults, respectively (World Health Organization [WHO], 2011). Obesity, in turn, is an important risk factor for diabetes, a metabolic disease associated to chronic hyperglycemia and an array of other complications (Tebay et al., 2015). A HFD (typically $40-60 \%$ of total calorie intake from fat) in humans and animals results in an augmented vulnerability to an array of medical conditions, including many psychiatric disorders where risk positively correlates with BMI (Lopes et al., 2001; Degirmenci et al., 2015). High BMI in human subjects is also linked to reduced blood flow in brain regions important for cognitive function (Willeumier et al., 2011) and reduced brain integrity (Gazdzinski et al., 2008; Stanek et al., 2011). Even a short-term HFD, for only 7 days, can cause cognitive impairment in humans (Edwards et al., 2011).

Accumulating data clearly shows that obesity is a risk factor for cognitive decline, dementia and neurodegenerative diseases, such as AD and PD (Mazon et al., 2017). One of the mechanisms by which diet-induced obesity can lead to neurological disorders is through increased neuroinflammation and ROS production and the downregulation of endogenous antioxidant enzymes, resulting in increased oxidative damage to the CNS (Edwards et al., 2011; Matsuda and Shimomura, 2013; Guillemot-Legris and Muccioli, 2017; Mazon et al., 2017). Diet-induced obesity can also lead to neurological disorders through microglia activation and $\mathrm{BBB}$ disruption, which can trigger neuroinflammation and synaptic impairment, thereby resulting in cognitive decline and neurodegeneration (Pistell et al., 2010; Zlokovic, 2011; Knight et al., 2014; Tucsek et al., 2014) (Figure 3).

Nrf2 activation can improve energy expenditure and prevent weight gain in HFD mice (Shin et al., 2009). Moreover, Nrf2/HO1 pathway activation can ameliorate long-term HFD-induced cognitive impairment, inflammation, as well as the accumulation of $\mathrm{A} \beta$ and hyperphosphorilated tau in the hippocampus (FangFang et al., 2017). In young subjects, Nrf2 can counteract the vascular oxidative damage and augmented ROS production associated with obesity (Ungvari et al., 2011a; Csiszar et al., 2015). However, aging is associated with Nrf2/ARE signaling pathway dysfunction, increasing the susceptibility of the elderly to obesity-driven oxidative stress. As oxidative stress is already exacerbated in these individuals by various other factors, the dysfunctioning of $\mathrm{Nrf} 2$ signaling will further aggravate this pro-oxidative scenario and contribute to the development of neuropsychiatric disorders in the aging brain (Morrison et al., 2010; Ungvari et al., 2011b,c).

Morrison et al. (2010) showed that 20-month old male mice fed a HFD composed of $60 \%$ fat, but not $41 \%$ fat, presented increased hippocampal oxidative stress and cognitive decline after 4 months, when compared to controls. These changes were associated with a decrease in Nrf2 levels and activity, suggesting that Nrf2 signaling impairment may be a mechanism of HFDinduced cognitive dysfunction in the aging brain.

Interestingly, numerous studies have demonstrated that DER can counteract the negative effects of HFD and promote a wide array of beneficial effects on the health of overweight individuals (Mattson, 2012). For instance, obese or overweight individuals show improved cognitive function and mood regulation following 12 months of DER (low carbohydrate or fat intake) (Brinkworth et al., 2009).

A HFD can result in neuronal insulin resistance, a marker of diabetes, contributing to cognitive impairment. Moreover, $\mathrm{AD}$ risk is positively correlated to brain insulin resistance and diabetes (Pipatpiboon et al., 2012; Tucsek et al., 2014; FangFang et al., 2017). Studies in an AD murine model show that, unlike DER, HFD and T2D symptoms can aggravate $\mathrm{A} \beta$ deposition in the brain and contribute to cognitive impairment (Ho et al., 2004; Takeda et al., 2010). In an AD post-mortem study, insulin resistance positively correlated with $\mathrm{A} \beta$ plaques and negatively correlated with last recorded cognitive function (Talbot et al., 2012).

A recent study in triple transgenic $\mathrm{AD}$ mice showed that HFD (60\% fat) for 4 months resulted in cognitive impairment, coupled to increased oxidative stress and neuronal cell death. These changes were attributed to suppressed Nrf2/ARE pathway activation along with reduced expression of the Nrf2 target genes 


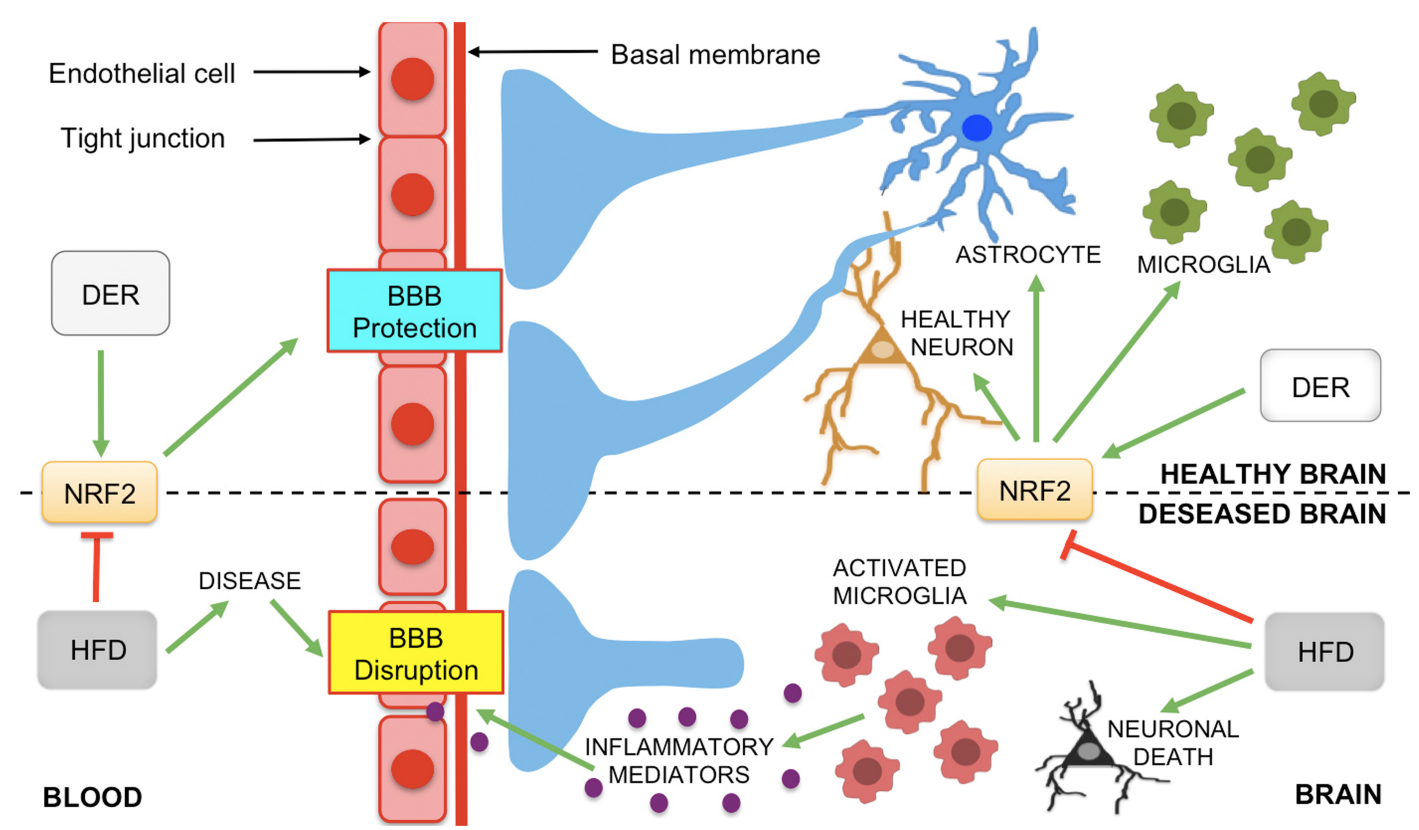

FIGURE 3 | The role of NRF2 and dietary interventions (DER and HFD) on the modification of the BBB. Neurological diseases, such as AD, PD, MS, and ischemic stroke, can lead to BBB disruption. However, Nrf2 protects neurons and the BBB against oxidative stress and inflammation-induced damage. Astrocytes, microglia and neurons produce Nrf2 that activates the expression of antioxidant and anti-inflammatory genes to the maintenance of neuronal health and BBB integrity. Nrf2 protective effects on BBB can be modulated by DER and HFD, modifying the release of inflammatory mediators by glial cells in neurodegenerative diseases. Green arrows represent activation and truncated red lines, inhibition (abbreviations: BBB, blood-brain barrier; DER, dietary energy restriction; HFD, high-fat diet, MS, multiple sclerosis; PD, Parkinson's disease; DER, dietary energy restriction; HFD, high-fat diet).

HO-1 and manganese SOD (MnSOD) (Sah et al., 2017). Tarantini et al. (2018) fed Nrf2 knockout mice a HFD (60\% fat) for 5 months, with Nrf2 deficiency significantly increasing HFDinduced brain inflammation, oxidative stress, synaptic disruption and $\mathrm{BBB}$ permeability, as well as raising levels of amyloid precursor protein (APP) gene expression, the proteolysis of which produces $A \beta$. The authors concluded that Nrf2 dysfunction exacerbates the obesity-induced adverse effects in the brain and plays a role in vascular cognitive impairment and AD (Tarantini et al., 2018).

As with $\mathrm{AD}$, calorie intake throughout life can influence the incidence of PD in some individuals (Mattson, 2012). Several lines of evidence have shown that diet, adiposity and T2D are linked to PD (Logroscino et al., 1996; Anderson et al., 1999; Johnson et al., 1999; Abbott et al., 2002; Hu et al., 2006, 2007; Morris et al., 2011; Schernhammer et al., 2011; Xu et al., 2011). All these factors are correlated to a HFD, given that over $80 \%$ of T2D patients are overweight or obese, whilst a HFD is frequently used as a model of diabetes (Centers for Disease Control and Prevention (CDC), 2004; Morris et al., 2011).

Many studies have shown that a HFD renders SN neurons more vulnerable to PD neurotoxins and increased ROS levels (Choi et al., 2005; Morris et al., 2010, 2011; Bousquet et al., 2012). In one of these works, mice fed a HFD or control diet for 5 weeks were treated with the PD-related neurotoxin 6-OHDA, with the HFD mice presenting with higher oxidative stress and neurodegeneration (dopamine depletion in the striatum and SN). These poorer outcomes were all correlated with heightened levels of adiposity and insulin resistance (Morris et al., 2010).

Innate and adaptive immune systems have a pivotal role in MS pathogenesis. Nrf2 agonists are promising candidates in the treatment of MS, since CDDO-Im 1-[2-cyano-3-,12dioxooleana-1,9(11)-dien-28-oyl] imidazole, a Nrf2 activator, promoting the differentiation of the less inflammatory Th2 $\mathrm{t}$ cell phenotype in stimulated splenocytes of C57BL/6 mice, thereby lowering INF $\gamma$ and TNF $\alpha$ production as well as NF- $\kappa$ B DNA binding (Zagorski et al., 2018). However, it has more recently been proposed that inflammatory processes are secondary to primary cytodegenerative processes in some neural cells, such as oligodendrocytes and neurons, with some studies strongly suggesting that alterations in mitochondrial functioning, and consequent increase ROS, can drive the initial neurodegeneration in MS (Witte et al., 2014). Furthermore, increased oxidative stress is correlated with decreased Complex IV electron transport chain gene expression and Nrf2 activity in the non-lesioned gray matter of the frontal and parietal cortex, from post-mortem MS and control groups, suggesting that mitochondrial function is correlated with, if not regulated by, Nrf2 in MS (Pandit et al., 2009).

Epidemiological studies also indicate a positive correlation between MS severity and fatty acids intake, with a long-term, higher level saturated fat consumption being associated with an increased frequency of MS as well as augmented EAE symptomatology (Schwarz and Leweling, 2005; Thompson, 2008; Winer et al., 2009). Moreover, overweight and obese 20 -year olds 
have a higher risk of developing MS compared to those of normal weight (Hedstrom et al., 2014). Likewise, several other dietary compounds like tea, coffee, alcohol and sweets are connected with MS incidence (Antonovsky et al., 1965; Berr et al., 1989; Sepcic et al., 1993; Tola et al., 1994). Timmermans and colleagues showed an increased clinical score and proinflammatory genes (IL6, INF $\gamma$, and IL1 $\beta$ ), as well as higher levels of infiltrating CD3 $+\mathrm{T}$ cells in the CNS of female animals subjected to a HFD. Similarly, Fernandez-Real and Pickup (Fernandez-Real and Pickup, 2008) showed an increase in inflammatory cytokines, soluble adhesion molecules, and chemokines in the blood of obese people. Accordingly, the Nrf2 activator, CDDO-IM, prevented the body weight gain in animals submitted to HFD, partly by regulating expression of fatty acid synthesis and oxidation enzymes in the liver (Shin et al., 2009).

As in MS, a HFD also is a risk factor for cardiovascular diseases and cerebral ischemia. Recent research has revealed an increase in the prevalence of acute ischemic stroke in children and young adults, correlated with such risk factors, as obesity and lipid disorders (George et al., 2011). Impairment in vascular function is evident in male Wistar rats submitted to 8-week HFD before transient middle cerebral artery occlusion (MCAO), with HFD significantly increasing not only body weight and adiposity as well as associated processes, but also augmenting the infarct size in rats ( $\mathrm{Li}$ et al., 2013). Such data highlights how alterations in the regulation of energy intake are intimately linked to levels of $\mathrm{Nrf} 2$, in the regulation of susceptibility to, and severity of, a wide array of seemingly distinct medical conditions.

Interestingly, both HFD and lack of Nrf2 can increase infarct area after cerebral ischemia. Deutsch et al. (2009) demonstrated that HFD-rats submitted to cerebral ischemia by MCAO showed smaller lumens and thicker MCA walls, when compared to normal diet controls. This is attributed to increased expression of metalloproteinase- 2 expression and collagen-1 deposition, suggesting impairment on neurovascular functions (Deutsch et al., 2009; Osmond et al., 2010; Li et al., 2013). In another study, the volume infarct of Nrf2-deficient mice subjected to MCAO for $90 \mathrm{~min}$ and $24 \mathrm{~h}$ of reperfusion was increased when compared to the control group (Shah et al., 2007). Intracerebral ventricular pre-administration of tert-butylhydroquinone reduced the infarct area in the MCAO mouse brain (Shih et al., 2005). Corroborating these findings, pharmacological agonism of $\mathrm{Nrf} 2$, by dimethyl fumarate, reduced $\mathrm{NF}-\kappa \mathrm{B}$ activation and protected the calcium-activated potassium (BK) channel-mediated coronary vasodilatation in HFD mice (Lu et al., 2017). These findings suggest that both Nrf2 and HFD have important roles in neurovascular and cerebral ischemia modulation.

It is also of note that dietary impacts on the composition of the gut microbiome may be of some relevance to the data presented above. There is considerable interest in the role of gut microbiome changes in the etiology, course and treatment of $\mathrm{AD}$, PD, and MS (Anderson and Maes, 2017), mediated via changes in the gut-brain and gut-liver axes. By increasing gut permeability, gut bacteria and tiny fragments of partially digested food can trigger an immune reaction, with a wide array of consequences, including the possible production of $\alpha$-synuclein in the gut, and its transport via neurons to the brain in the etiology of PD (Chen et al., 2018). Generally, an increase in the gut bacteria producing the small chain fatty acid, butyrate, is beneficial across a wide array of medical conditions. It is of note that butyrate increases levels of Nrf2 (Anderson et al., 2016), suggesting that some of the benefits of butyrate may be mediated not only by its histone deacetylase inhibitor capacity and its induction of melatonin, but also by its induction of Nrf2 (Dong W. et al., 2017).

\section{CONCLUSION}

It is widely accepted that oxidative stress plays a central role in neurological disorders. This underpins the importance of targeting Nrf2 to counteract such oxidative stress and associated brain diseases (Patel, 2016). Dietary interventions such as DER protocols, in contrast to a HFD, can promote small energetic challenges to the brain that enhance Nrf2/ARE pathway activation (Mattson, 2012). Nrf2 up-regulates the expression of several pro-survival genes and counteracts oxidative damage to the CNS, thereby preventing neurodegeneration and obesityrelated brain disorders (Calkins et al., 2009). Hence, DER may be a valuable treatment option for brain disorders, including as adjunct therapy with other known Nrf2 activators. However, controversial reports showed that NRF2 activation can result in drug resistance and oncogenic effects (Sporn and Liby, 2012). Thus, additional large-scale studies are warranted to further explore the effects of dietary interventions in Nrf2/ARE signaling and to establish the best dietary protocols for humans to optimize the beneficial effects of Nrf2 for the prevention and/or early intervention in the etiology and course of neurological disorders.

\section{AUTHOR CONTRIBUTIONS}

$\mathrm{AV}, \mathrm{NdS}, \mathrm{CS}$, and CM contributed to the design of the manuscript, literature review, writing of the manuscript, and creation of the figures.

\section{FUNDING}

This publication was supported by grants from Fundação de Amparo à Pesquisa do Estado de São Paulo (FAPESP \#2012/24727-4 and \#2016/07427-8), Conselho Nacional de Desenvolvimento Científico e Tecnológico (CNPq \#160570/20123), and University of São Paulo (USP).

\section{ACKNOWLEDGMENTS}

The authors would like to thank George Anderson of CRC Scotland \& London for English editing services. 


\section{REFERENCES}

Abbott, R. D., Ross, G. W., White, L. R., Nelson, J. S., Masaki, K. H., Tanner, C. M., et al. (2002). Midlife adiposity, and the future risk of Parkinson's disease. Neurology 59, 1051-1057. doi: 10.1212/WNL.59.7.1051

Ahmad, W., Ijaz, B., Shabbiri, K., Ahmed, F., and Rehman, S. (2017). Oxidative toxicity in diabetes and Alzheimer's disease: mechanisms behind ROS/ RNS generation. J. Biomed. Sci. 24:76. doi: 10.1186/s12929-017-0379-z

Alfieri, A., Srivastava, S., Siow, R. C., Modo, M., Fraser, P. A., and Mann, G. E. (2011). Targeting the Nrf2-Keap1 antioxidant defence pathway for neurovascular protection in stroke. J. Physiol. 589, 4125-4136. doi: 10.1113/ jphysiol.2011.210294

Alfredsson, L., and Olsson, T. (2018). Lifestyle and environmental factors in multiple sclerosis. Cold Spring Harb. Perspect. Med. doi: 10.1101/cshperspect. a028944 [Epub ahead of print].

Al-Huseini, L. M., Aw Yeang, H. X., Sethu, S., Alhumeed, N., Hamdam, J. M., Tingle, Y., et al. (2013). Nuclear factor-erythroid 2 (NF-E2) p45-related factor2 (Nrf2) modulates dendritic cell immune function through regulation of p38 MAPK-cAMP-responsive element binding protein/activating transcription factor 1 signaling. J. Biol. Chem. 288, 22281-22288. doi: 10.1074/jbc.M113. 483420

Aluise, C. D., Robinson, R. A., Cai, J., Pierce, W. M., Markesbery, W. R., and Butterfield, D. A. (2011). Redox proteomics analysis of brains from subjects with amnestic mild cognitive impairment compared to brains from subjects with preclinical Alzheimer's disease: insights into memory loss in MCI. J. Alzheimers Dis. 23, 257-269. doi: 10.3233/JAD-2010-101083

Alzheimer's Association (2018). Alzheimer's disease facts and figures. Alzheimers Dement. 14, 367-429.

Anderson, C., Checkoway, H., Franklin, G. M., Beresford, S., Smith-Weller, T., and Swanson, P. D. (1999). Dietary factors in Parkinson's disease: the role of food groups and specific foods. Mov. Disord. 14, 21-27. doi: 10.1002/15318257(199901)14:1<21::AID-MDS1006>3.0.CO;2-Y

Anderson, G., and Maes, M. (2017). How immune-inflammatory processes link CNS and psychiatric disorders: classification and treatment implications. CNS Neurol. Disord. Drug Targets 16, 266-278. doi: 10.2174/1871527315666161122144659

Anderson, G., Seo, M., Berk, M., Carvalho, A. F., and Maes, M. (2016). Gut permeability and microbiota in Parkinson's disease: role of depression, tryptophan catabolites, oxidative and nitrosative stress and melatonergic pathways. Curr. Pharm. Des. 22, 6142-6151. doi: 10.2174/1381612822666160906161513

Antonovsky, A., Leibowitz, U., Smith, H. A., Medalie, J. M., Balogh, M., Kats, R., et al. (1965). Epidemiologic study of multiple sclerosis in Israel. I. An overall review of methods and findings. Arch. Neurol. 13, 183-193. doi: 10.1001/ archneur.1965.00470020073010

Arriagada, P. V., Growdon, J. H., Hedley-Whyte, E. T., and Hyman, B. T. (1992). Neurofibrillary tangles but not senile plaques parallel duration and severity of Alzheimer's disease. Neurology 42(3 Pt 1), 631-639. doi: 10.1212/WNL.42.3.631

Ascherio, A. (2013). Environmental factors in multiple sclerosis. Expert Rev. Neurother. 13(Suppl. 12), 3-9. doi: 10.1586/14737175.2013.865866

Bai, J., Yu, X. J., Liu, K. L., Wang, F. F., Jing, G. X., Li, H. B., et al. (2017). Central administration of tert-butylhydroquinone attenuates hypertension via regulating Nrf2 signaling in the hypothalamic paraventricular nucleus of hypertensive rats. Toxicol. Appl. Pharmacol. 333, 100-109. doi: 10.1016/j.taap. 2017.08.012

Ballatori, N., Krance, S. M., Notenboom, S., Shi, S., Tieu, K., and Hammond, C. L. (2009). Glutathione dysregulation and the etiology and progression of human diseases. Biol. Chem. 390, 191-214. doi: 10.1515/BC.2009.033

Balogun, E., Hoque, M., Gong, P., Killeen, E., Green, C. J., Foresti, R., et al. (2003). Curcumin activates the haem oxygenase-1 gene via regulation of $\mathrm{Nrf} 2$ and the antioxidant-responsive element. Biochem. J. 371(Pt 3), 887-895. doi: 10.1042/BJ20021619

Berer, K., Mues, M., Koutrolos, M., Rasbi, Z. A., Boziki, M., Johner, C., et al. (2011). Commensal microbiota and myelin autoantigen cooperate to trigger autoimmune demyelination. Nature 479, 538-541. doi: 10.1038/nature10554

Bermejo, P., Martin-Aragon, S., Benedi, J., Susin, C., Felici, E., Gil, P., et al. (2008). Peripheral levels of glutathione and protein oxidation as markers in the development of Alzheimer's disease from Mild Cognitive Impairment. Free Radic. Res. 42, 162-170. doi: 10.1080/10715760701861373

Berr, C., Puel, J., Clanet, M., Ruidavets, J. B., Mas, J. L., and Alperovitch, A. (1989). Risk factors in multiple sclerosis: a population-based case-control study in Hautes-Pyrenees, France. Acta Neurol. Scand. 80, 46-50. doi: 10.1111/j.16000404.1989.tb03841.x

Blesa, J., Trigo-Damas, I., Quiroga-Varela, A., and Jackson-Lewis, V. R. (2015). Oxidative stress and Parkinson's disease. Front. Neuroanat. 9:91. doi: 10.3389/ fnana.2015.00091

Bo, L., Dawson, T. M., Wesselingh, S., Mork, S., Choi, S., Kong, P. A., et al. (1994). Induction of nitric oxide synthase in demyelinating regions of multiple sclerosis brains. Ann. Neurol. 36, 778-786. doi: 10.1002/ana.410360515

Bousquet, M., St-Amour, I., Vandal, M., Julien, P., Cicchetti, F., and Calon, F. (2012). High-fat diet exacerbates MPTP-induced dopaminergic degeneration in mice. Neurobiol. Dis. 45, 529-538. doi: 10.1016/j.nbd.2011.09.009

Bradley, M. A., Xiong-Fister, S., Markesbery, W. R., and Lovell, M. A. (2012). Elevated 4-hydroxyhexenal in Alzheimer's disease (AD) progression. Neurob. Aging 33, 1034-1044. doi: 10.1016/j.neurobiolaging.2010.08.016

Brinkworth, G. D., Buckley, J. D., Noakes, M., Clifton, P. M., and Wilson, C. J. (2009). Long-term effects of a very low-carbohydrate diet and a low-fat diet on mood and cognitive function. Arch. Intern. Med. 169, 1873-1880. doi: 10.1001/ archinternmed.2009.329

Bruns, D. R., Drake, J. C., Biela, L. M., Peelor, F. F. III, Miller, B. F., and Hamilton, K. L. (2015). Nrf2 signaling and the slowed aging phenotype: evidence from long-lived models. Oxid. Med. Cell. Longev. 2015:732596. doi: 10.1155/2015/ 732596

Buendia, I., Michalska, P., Navarro, E., Gameiro, I., Egea, J., and Leon, R. (2016). Nrf2-ARE pathway: an emerging target against oxidative stress and neuroinflammation in neurodegenerative diseases. Pharmacol. Ther. 157, 84104. doi: 10.1016/j.pharmthera.2015.11.003

Cai, Z., Zhao, B., and Ratka, A. (2011). Oxidative stress and beta-amyloid protein in Alzheimer's disease. Neuromol. Med. 13, 223-250. doi: 10.1007/s12017-0118155-9

Calabrese, V., Cornelius, C., Dinkova-Kostova, A. T., Calabrese, E. J., and Mattson, M. P. (2010). Cellular stress responses, the hormesis paradigm, and vitagenes: novel targets for therapeutic intervention in neurodegenerative disorders. Antioxid. Redox Signal. 13, 1763-1811. doi: 10.1089/ars.2009.3074

Calder, P. C., Ahluwalia, N., Brouns, F., Buetler, T., Clement, K., Cunningham, K., et al. (2011). Dietary factors and low-grade inflammation in relation to overweight and obesity. Br. J. Nutr. 106(Suppl. 3), S5-S78. doi: 10.1017/ S0007114511005460

Calkins, M. J., Johnson, D. A., Townsend, J. A., Vargas, M. R., Dowell, J. A., Williamson, T. P., et al. (2009). The Nrf2/ARE pathway as a potential therapeutic target in neurodegenerative disease. Antioxid. Redox Signal. 11, 497-508. doi: 10.1089/ARS.2008.2242

Cao, T. T., Ma, L., Kandpal, G., Warren, L., Hess, J. F., and Seabrook, G. R. (2005) Increased nuclear factor-erythroid 2 p45-related factor 2 activity protects $\mathrm{SH}$ SY5Y cells against oxidative damage. J. Neurochem. 95, 406-417. doi: 10.1111/j. 1471-4159.2005.03377.x

Caro, J. F., Sinha, M. K., Kolaczynski, J. W., Zhang, P. L., and Considine, R. V. (1996). Leptin: the tale of an obesity gene. Diabetes 45, 1455-1462. doi: 10.2337/ diab.45.11.1455

Carvalho, C., Santos, M. S., Oliveira, C. R., and Moreira, P. I. (2015). Alzheimer's disease and type 2 diabetes-related alterations in brain mitochondria, autophagy and synaptic markers. Biochim. Biophys. Acta 1852, 1665-1675. doi: 10.1016/j. bbadis.2015.05.001

Centers for Disease Control and Prevention (CDC) (2004). Prevalence of overweight and obesity among adults with diagnosed. (diabetes)-United States, 1988-1994 and 1999-2002. MMWR Morb. Mortal. Wkly. Rep. 53, 1066-1068. doi: 10.1016/j.bbrc.2005.03.237

Chen, C. Y., Jang, J. H., Li, M. H., and Surh, Y. J. (2005). Resveratrol upregulates heme oxygenase-1 expression via activation of NF-E2-related factor 2 in PC12 cells. Biochem. Biophys. Res. Commun. 331, 993-1000. doi: 10.1016/j.bbrc.2005. 03.237

Chen, J., Chia, N., Kalari, K. R., Yao, J. Z., Novotna, M., Paz Soldan, M. M., et al. (2016a). Multiple sclerosis patients have a distinct gut microbiota compared to healthy controls. Sci. Rep. 6:28484. doi: 10.1038/srep28484 
Chen, J. W., Breckwoldt, M. O., Aikawa, E., Chiang, G., and Weissleder, R. (2008). Myeloperoxidase-targeted imaging of active inflammatory lesions in murine experimental autoimmune encephalomyelitis. Brain 131(Pt 4), 1123-1133. doi: 10.1093/brain/awn004

Chen, K., Gunter, K., and Maines, M. D. (2000). Neurons overexpressing heme oxygenase-1 resist oxidative stress-mediated cell death. J. Neurochem. 75, 304313. doi: 10.1046/j.1471-4159.2000.0750304.x

Chen, L. H., Hu, N., and Snyder, D. L. (1994). Effects of age and dietary restriction on liver glutathione transferase activities in Lobund-Wistar rats. Arch. Gerontol. Geriatr. 18, 191-205. doi: 10.1016/0167-4943(94)90013-2

Chen, P. C., Vargas, M. R., Pani, A. K., Smeyne, R. J., Johnson, D. A., Kan, Y. W., et al. (2009). Nrf2-mediated neuroprotection in the MPTP mouse model of Parkinson's disease: critical role for the astrocyte. Proc. Natl. Acad. Sci. U.S.A. 106, 2933-2938. doi: 10.1073/pnas.0813361106

Chen, W. W., Zhang, X., and Huang, W. J. (2016b). Role of neuroinflammation in neurodegenerative diseases (Review). Mol. Med. Rep. 13, 3391-3396. doi: 10.3892/mmr.2016.4948

Chen, Y., Shao, Q., Yuan, Y. H., and Chen, N. H. (2018). Prion-like propagation of alpha-synuclein in the gut-brain axis. Brain Res. Bull. 140, 341-346. doi: 10.1016/j.brainresbull.2018.06.002

Chhetri, J., King, A. E., and Gueven, N. (2018). Alzheimer's Disease and NQO1: is there a Link? Curr. Alzheimer Res. 15, 56-66. doi: 10.2174/ 1567205014666170203095802

Chiaravalloti, N. D., and DeLuca, J. (2008). Cognitive impairment in multiple sclerosis. Lancet Neurol. 7, 1139-1151. doi: 10.1016/S1474-4422(08)70259-X

Cho, C. G., Kim, H. J., Chung, S. W., Jung, K. J., Shim, K. H., Yu, B. P., et al. (2003). Modulation of glutathione and thioredoxin systems by calorie restriction during the aging process. Exp. Gerontol. 38, 539-548. doi: 10.1016/ S0531-5565(03)00005-6

Choi, J. Y., Jang, E. H., Park, C. S., and Kang, J. H. (2005). Enhanced susceptibility to 1-methyl-4-phenyl-1,2,3,6-tetrahydropyridine neurotoxicity in high-fat diet-induced obesity. Free Radic. Biol. Med. 38, 806-816. doi: 10.1016/ j.freeradbiomed.2004.12.008

Colton, C. A. (2009). Heterogeneity of microglial activation in the innate immune response in the brain. J. Neuroimmune Pharmacol. 4, 399-418. doi: 10.1007/ s11481-009-9164-4

Csiszar, A., Csiszar, A., Pinto, J. T., Gautam, T., Kleusch, C., Hoffmann, B., et al. (2015). Resveratrol encapsulated in novel fusogenic liposomes activates Nrf2 and attenuates oxidative stress in cerebromicrovascular endothelial cells from aged rats. J. Gerontol. Ser. A Biol. Sci. Med. Sci. 70, 303-313. doi: 10.1093/ gerona/glu029

Csiszar, A., Gautam, T., Sosnowska, D., Tarantini, S., Banki, E., Tucsek, Z., et al. (2014). Caloric restriction confers persistent anti-oxidative, pro-angiogenic, and anti-inflammatory effects and promotes anti-aging miRNA expression profile in cerebromicrovascular endothelial cells of aged rats. Am. J. Physiol. Heart Circ. Physiol. 307, H292-H306. doi: 10.1152/ajpheart.00307.2014

Cuadrado, A. (2016). NRF2 in neurodegenerative diseases. Curr. Opin. Toxicol. 1, 46-53. doi: 10.1016/j.cotox.2016.09.004

Cuadrado, A., Moreno-Murciano, P., and Pedraza-Chaverri, J. (2009). The transcription factor Nrf2 as a new therapeutic target in Parkinson's disease. Expert Opin. Ther. Targets 13, 319-329. doi: 10.1517/13543780802716501

De Cabo, R., Cabello, R., Rios, M., Lopez-Lluch, G., Ingram, D. K., Lane, M. A., et al. (2004). Calorie restriction attenuates age-related alterations in the plasma membrane antioxidant system in rat liver. Exp. Gerontol. 39, 297-304. doi: 10.1016/j.exger.2003.12.003

De Groot, C. J., Ruuls, S. R., Theeuwes, J. W., Dijkstra, C. D., and Van der Valk, P. (1997). Immunocytochemical characterization of the expression of inducible and constitutive isoforms of nitric oxide synthase in demyelinating multiple sclerosis lesions. J. neuropathol. Exp. Neurol. 56, 10-20. doi: 10.1097/00005072199701000-00002

Degirmenci, T., Kalkan-Oguzhanoglu, N., Sozeri-Varma, G., Ozdel, O., and Fenkci, S. (2015). Psychological symptoms in obesity and related factors. Noro Psikiyatr. Ars. 52, 42-46. doi: 10.5152/npa.2015.6904

DeNicola, G. M., Karreth, F. A., Humpton, T. J., Gopinathan, A., Wei, C., Frese, K., et al. (2011). Oncogene-induced Nrf2 transcription promotes ROS detoxification and tumorigenesis. Nature 475, 106-109. doi: 10.1038/ nature10189
Deutsch, C., Portik-Dobos, V., Smith, A. D., Ergul, A., and Dorrance, A. M. (2009). Diet-induced obesity causes cerebral vessel remodeling and increases the damage caused by ischemic stroke. Microvasc. Res. 78, 100-106. doi: 10. 1016/j.mvr.2009.04.004

Di Domenico, F., Tramutola, A., and Butterfield, D. A. (2017). Role of 4-hydroxy2-nonenal (HNE) in the pathogenesis of alzheimer disease and other selected age-related neurodegenerative disorders. Free Radic. Biol. Med. 111, 253-261. doi: 10.1016/j.freeradbiomed.2016.10.490

Ding, Y., Ren, D., Xu, H., Liu, W., Liu, T., Li, L., et al. (2017). Antioxidant and pro-angiogenic effects of corilagin in rat cerebral ischemia via Nrf2 activation. Oncotarget 8, 114816-114828. doi: 10.18632/oncotarget.22023

Ding, Y., Zhang, B., Zhou, K., Chen, M., Wang, M., Jia, Y., et al. (2014). Dietary ellagic acid improves oxidant-induced endothelial dysfunction and atherosclerosis: role of Nrf2 activation. Int. J. Cardiol. 175, 508-514. doi: 10. 1016/j.ijcard.2014.06.045

Dong, F., Wang, S., Wang, Y., Yang, X., Jiang, J., Wu, D., et al. (2017). Quercetin ameliorates learning and memory via the Nrf2-ARE signaling pathway in d-galactose-induced neurotoxicity in mice. Biochem. Biophys. Res. Commun. 491, 636-641. doi: 10.1016/j.bbrc.2017.07.151

Dong, W., Jia, Y., Liu, X., Zhang, H., Li, T., Huang, W., et al. (2017). Sodium butyrate activates NRF2 to ameliorate diabetic nephropathy possibly via inhibition of HDAC. J. Endocrinol. 232, 71-83. doi: 10.1530/JOE-16-0322

Dorrance, A. M., Matin, N., and Pires, P. W. (2014). The effects of obesity on the cerebral vasculature. Curr. Vasc. Pharmacol. 12, 462-472. doi: 10.2174/ 1570161112666140423222411

Duan, W., and Mattson, M. P. (1999). Dietary restriction and 2-deoxyglucose administration improve behavioral outcome and reduce degeneration of dopaminergic neurons in models of Parkinson's disease. J. Neurosci. Res. 57, 195-206. doi: 10.1002/(SICI)1097-4547(19990715)57:2<195::AID-JNR5>3. $0 . \mathrm{CO} ; 2-\mathrm{P}$

Edwards, L. M., Murray, A. J., Holloway, C. J., Carter, E. E., Kemp, G. J., Codreanu, I., et al. (2011). Short-term consumption of a high-fat diet impairs whole-body efficiency and cognitive function in sedentary men. FASEB J. 25, 1088-1096. doi: 10.1096/fj.10-171983

FangFang, Li, H., Qin, T., Li, M., and Ma, S. (2017). Thymol improves high-fat diet-induced cognitive deficits in mice via ameliorating brain insulin resistance and upregulating NRF2/HO-1 pathway. Metab. Brain Dis. 32, 385-393. doi: 10.1007/s11011-016-9921-z

Farombi, E. O., Shrotriya, S., Na, H. K., Kim, S. H., and Surh, Y. J. (2008). Curcumin attenuates dimethylnitrosamine-induced liver injury in rats through Nrf2mediated induction of heme oxygenase-1. Food Chem. Toxicol. 46, 1279-1287. doi: 10.1016/j.fct.2007.09.095

Fernandez-Real, J. M., and Pickup, J. C. (2008). Innate immunity, insulin resistance and type 2 diabetes. Trends Endocrinol. Metab. 19, 10-16. doi: 10.1016/j.tem. 2007.10.004

Frank, M. G., Baratta, M. V., Sprunger, D. B., Watkins, L. R., and Maier, S. F. (2007). Microglia serve as a neuroimmune substrate for stress-induced potentiation of CNS pro-inflammatory cytokine responses. Brain Behav. Immun. 21, 47-59. doi: 10.1016/j.bbi.2006.03.005

French, H. M., Reid, M., Mamontov, P., Simmons, R. A., and Grinspan, J. B. (2009). Oxidative stress disrupts oligodendrocyte maturation. J. Neurosci. Res. 87, 3076-3087. doi: 10.1002/jnr.22139

Furusawa, Y., Obata, Y., and Hase, K. (2015). Commensal microbiota regulates $\mathrm{T}$ cell fate decision in the gut. Semin. Immunopathol. 37, 17-25. doi: 10.1007/ s00281-014-0455-3

Gavillet, M., Allaman, I., and Magistretti, P. J. (2008). Modulation of astrocytic metabolic phenotype by proinflammatory cytokines. Glia 56, 975-989. doi: 10.1002/glia.20671

Gazdzinski, S., Kornak, J., Weiner, M. W., and Meyerhoff, D. J. (2008). Body mass index and magnetic resonance markers of brain integrity in adults. Ann. Neurol. 63, 652-657. doi: 10.1002/ana.21377

George, M. G., Tong, X., Kuklina, E. V., and Labarthe, D. R. (2011). Trends in stroke hospitalizations and associated risk factors among children and young adults, 1995-2008. Ann. Neurol. 70, 713-721. doi: 10.1002/ana.22539

Giordano, G., White, C. C., Mohar, I., Kavanagh, T. J., and Costa, L. G. (2007). Glutathione levels modulate domoic acid induced apoptosis in mouse cerebellar granule cells. Toxicol. Sci. 100, 433-444. doi: 10.1093/toxsci/kfm236 
Glass, C. K., Saijo, K., Winner, B., Marchetto, M. C., and Gage, F. H. (2010). Mechanisms underlying inflammation in neurodegeneration. Cell 140, 918 934. doi: 10.1016/j.cell.2010.02.016

Go, K. G., Prenen, G. H., and Korf, J. (1988). Protective effect of fasting upon cerebral hypoxic-ischemic injury. Metab. Brain Dis. 3, 257-263. doi: 10.1007/ BF00999535

Gorelick, P. B., Scuteri, A., Black, S. E., Decarli, C., Greenberg, S. M., Iadecola, C., et al. (2011). Vascular contributions to cognitive impairment and dementia: a statement for healthcare professionals from the American heart association/american stroke association. Stroke 42, 2672-2713. doi: 10.1161/ STR.0b013e3182299496

Goris, A., Williams-Gray, C. H., Clark, G. R., Foltynie, T., Lewis, S. J., Brown, J., et al. (2007). Tau and alpha-synuclein in susceptibility to, and dementia in, Parkinson's disease. Ann. Neurol. 62, 145-153. doi: 10.1002/ana.21192

Goto, Y., Panea, C., Nakato, G., Cebula, A., Lee, C., Diez, M. G., et al. (2014). Segmented filamentous bacteria antigens presented by intestinal dendritic cells drive mucosal Th17 cell differentiation. Immunity 40, 594-607. doi: 10.1016/j. immuni.2014.03.005

Gray, E., Thomas, T. L., Betmouni, S., Scolding, N., and Love, S. (2008a). Elevated activity and microglial expression of myeloperoxidase in demyelinated cerebral cortex in multiple sclerosis. Brain Pathol. 18, 86-95. doi: 10.1111/j.1750-3639. 2007.00110.x

Gray, E., Thomas, T. L., Betmouni, S., Scolding, N., and Love, S. (2008b). Elevated myeloperoxidase activity in white matter in multiple sclerosis. Neurosci. Lett. 444, 195-198. doi: 10.1016/j.neulet.2008.08.035

Griffioen, K. J., Rothman, S. M., Ladenheim, B., Wan, R., Vranis, N., Hutchison, E., et al. (2013). Dietary energy intake modifies brainstem autonomic dysfunction caused by mutant alpha-synuclein. Neurobiol. Aging 34, 928-935. doi: 10.1016/ j.neurobiolaging.2012.07.008

Guillemot-Legris, O., and Muccioli, G. G. (2017). Obesity-induced neuroinflammation: beyond the hypothalamus. Trends Neurosci. 40, 237-253. doi: 10.1016/j.tins.2017.02.005

Gursoy-Ozdemir, Y., Can, A., and Dalkara, T. (2004). Reperfusion-induced oxidative/nitrative injury to neurovascular unit after focal cerebral ischemia. Stroke 35, 1449-1453. doi: 10.1161/01.STR.0000126044.83777.f4

Halagappa, V. K., Guo, Z., Pearson, M., Matsuoka, Y., Cutler, R. G., Laferla, F. M., et al. (2007). Intermittent fasting and caloric restriction ameliorate age-related behavioral deficits in the triple-transgenic mouse model of Alzheimer's disease. Neurobiol. Dis. 26, 212-220. doi: 10.1016/j.nbd.2006.12.019

Hara, H., Ohta, M., and Adachi, T. (2006). Apomorphine protects against 6hydroxydopamine-induced neuronal cell death through activation of the Nrf2ARE pathway. J. Neurosci. Res. 84, 860-866. doi: 10.1002/jnr.20974

Hedstrom, A. K., Lima Bomfim, I., Barcellos, L., Gianfrancesco, M., Schaefer, C., Kockum, I., et al. (2014). Interaction between adolescent obesity and HLA risk genes in the etiology of multiple sclerosis. Neurology 82, 865-872. doi: 10.1212/WNL.0000000000000203

Hedstrom, A. K., Olsson, T., and Alfredsson, L. (2012). High body mass index before age 20 is associated with increased risk for multiple sclerosis in both men and women. Mult. Scler. 18, 1334-1336. doi: 10.1177/1352458512436596

Herrmann, T. S., Bean, M. L., Black, T. M., Wang, P., and Coleman, R. A. (2001). High glycemic index carbohydrate diet alters the diurnal rhythm of leptin but not insulin concentrations. Exp. Biol. Med. 226, 1037-1044. doi: 10.1177/ 153537020122601111

Higgins, L. G., Kelleher, M. O., Eggleston, I. M., Itoh, K., Yamamoto, M., and Hayes, J. D. (2009). Transcription factor Nrf2 mediates an adaptive response to sulforaphane that protects fibroblasts in vitro against the cytotoxic effects of electrophiles, peroxides and redox-cycling agents. Toxicol. Appl. Pharmacol. 237, 267-280. doi: 10.1016/j.taap.2009.03.005

Hine, C. M., and Mitchell, J. R. (2012). NRF2 and the phase II response in acute stress resistance induced by dietary restriction. J. Clin. Exp. Pathol. S4:7329. doi: 10.4172/2161-0681.S4-004

Ho, L., Qin, W., Pompl, P. N., Xiang, Z., Wang, J., Zhao, Z., et al. (2004). Dietinduced insulin resistance promotes amyloidosis in a transgenic mouse model of Alzheimer's disease. FASEB J. 18, 902-904. doi: 10.1096/fj.03-0978fje

Holmer, H. K., Keyghobadi, M., Moore, C., Menashe, R. A., and Meshul, C. K. (2005). Dietary restriction affects striatal glutamate in the MPTP-induced mouse model of nigrostriatal degeneration. Synapse 57, 100-112. doi: 10.1002/ syn. 20163
Holmstrom, K. M., Baird, L., Zhang, Y., Hargreaves, I., Chalasani, A., Land, J. M., et al. (2013). Nrf2 impacts cellular bioenergetics by controlling substrate availability for mitochondrial respiration. Biol. Open 2, 761-770. doi: 10.1242/ bio. 20134853

Horne, B. D., Muhlestein, J. B., and Anderson, J. L. (2015). Health effects of intermittent fasting: hormesis or harm? A systematic review. Am. J. Clin. Nutr. 102, 464-470. doi: 10.3945/ajcn.115.109553

Hsieh, T. C., Lu, X., Wang, Z., and Wu, J. M. (2006). Induction of quinone reductase NQO1 by resveratrol in human K562 cells involves the antioxidant response element ARE and is accompanied by nuclear translocation of transcription factor Nrf2. Med. Chem. 2, 275-285. doi: 10.2174/ 157340606776930709

Hu, G., Jousilahti, P., Bidel, S., Antikainen, R., and Tuomilehto, J. (2007). Type 2 diabetes and the risk of Parkinson's disease. Diabetes Care 30, 842-847. doi: $10.2337 / \mathrm{dc} 06-2011$

Hu, G., Jousilahti, P., Nissinen, A., Antikainen, R., Kivipelto, M., and Tuomilehto, J. (2006). Body mass index, and the risk of Parkinson disease. Neurology 67, 1955-1959. doi: 10.1212/01.wnl.0000247052.18422.e5

Huang, Y., Mao, Y., Li, H., Shen, G., and Nan, G. (2018). Knockdown of Nrf2 inhibits angiogenesis by downregulating VEGF expression through PI3K/Akt signaling pathway in cerebral microvascular endothelial cells under hypoxic conditions. Biochem. Cell Biol. 96, 475-482. doi: 10.1139/bcb-2017-0291

Huang, Y. J., Zhang, L., Shi, L. Y., Wang, Y. Y., Yang, Y. B., Ke, B., et al. (2018). Caloric restriction ameliorates acrolein-induced neurotoxicity in rats. Neurotoxicology 65, 44-51. doi: 10.1016/j.neuro.2018.01.003

Hwang, Y. P., and Jeong, H. G. (2008). The coffee diterpene kahweol induces heme oxygenase-1 via the PI3K and $\mathrm{p} 38 / \mathrm{Nrf} 2$ pathway to protect human dopaminergic neurons from 6-hydroxydopamine-derived oxidative stress. FEBS Lett. 582, 2655-2662. doi: 10.1016/j.febslet.2008.06.045

Hyun, D. H., Emerson, S. S., Jo, D. G., Mattson, M. P., and de Cabo, R. (2006). Calorie restriction up-regulates the plasma membrane redox system in brain cells and suppresses oxidative stress during aging. Proc. Natl. Acad. Sci. U.S.A. 103, 19908-19912. doi: 10.1073/pnas.0608008103

Ingram, D. K., Zhu, M., Mamczarz, J., Zou, S., Lane, M. A., Roth, G. S., et al. (2006). Calorie restriction mimetics: an emerging research field. Aging Cell 5, 97-108. doi: 10.1111/j.1474-9726.2006.00202.x

Inoue, M., Williams, K. L., Gunn, M. D., and Shinohara, M. L. (2012). NLRP3 inflammasome induces chemotactic immune cell migration to the CNS in experimental autoimmune encephalomyelitis. Proc. Natl. Acad. Sci. U.S.A. 109, 10480-10485. doi: 10.1073/pnas.1201836109

Itoh, K., Chiba, T., Takahashi, S., Ishii, T., Igarashi, K., Katoh, Y., et al. (1997). An Nrf2/small Maf heterodimer mediates the induction of phase II detoxifying enzyme genes through antioxidant response elements. Biochem. Biophys. Res. Commun. 236, 313-322. doi: 10.1006/bbrc.1997.6943

Jaiswal, A. K. (2004). Nrf2 signaling in coordinated activation of antioxidant gene expression. Free Radic. Biol. Med. 36, 1199-1207. doi: 10.1016/j.freeradbiomed. 2004.02.074

Jakel, R. J., Townsend, J. A., Kraft, A. D., and Johnson, J. A. (2007). Nrf2-mediated protection against 6-hydroxydopamine. Brain Res. 1144, 192-201. doi: 10.1016/ j.brainres.2007.01.131

Jangi, S., Gandhi, R., Cox, L. M., Li, N., von Glehn, F., Yan, R., et al. (2016). Alterations of the human gut microbiome in multiple sclerosis. Nat. Commun. 7:12015. doi: 10.1038/ncomms12015

Jauch, E. C., Saver, J. L., Adams, H. P. Jr., Bruno, A., Connors, J. J., Demaerschalk, B. M., et al. (2013). Guidelines for the early management of patients with acute ischemic stroke: a guideline for healthcare professionals from the American Heart Association/American Stroke Association. Stroke 44, 870-947. doi: 10. 1161/STR.0b013e318284056a

Jazwa, A., Rojo, A. I., Innamorato, N. G., Hesse, M., Fernandez-Ruiz, J., and Cuadrado, A. (2011). Pharmacological targeting of the transcription factor $\mathrm{Nrf} 2$ at the basal ganglia provides disease modifying therapy for experimental parkinsonism. Antioxid. Redox Signal. 14, 2347-2360. doi: 10.1089/ars.2010. 3731

Jenner, P. (2007). Oxidative stress and Parkinson's disease. Handb. Clin. Neurol. 83, 507-520. doi: 10.1016/S0072-9752(07)83024-7

Jo, C., Gundemir, S., Pritchard, S., Jin, Y. N., Rahman, I., and Johnson, G. V. (2014). Nrf2 reduces levels of phosphorylated tau protein by inducing autophagy adaptor protein NDP52. Nat. Commun. 5:3496. doi: 10.1038/ncomms4496 
Johnson, C. C., Gorell, J. M., Rybicki, B. A., Sanders, K., and Peterson, E. L. (1999). Adult nutrient intake as a risk factor for Parkinson's disease. Int. J. Epidemiol. 28, 1102-1109. doi: 10.1093/ije/28.6.1102

Johnson, D. A., Amirahmadi, S., Ward, C., Fabry, Z., and Johnson, J. A. (2010). The absence of the pro-antioxidant transcription factor Nrf2 exacerbates experimental autoimmune encephalomyelitis. Toxicol. Sci. 114, 237-246. doi: $10.1093 /$ toxsci/kfp274

Joshi, G., Gan, K. A., Johnson, D. A., and Johnson, J. A. (2015). Increased Alzheimer's disease-like pathology in the APP/ PS1DeltaE9 mouse model lacking Nrf2 through modulation of autophagy. Neurobiol. Aging 36, 664-679. doi: 10.1016/j.neurobiolaging.2014.09.004

Juurlink, B. H., Thorburne, S. K., and Hertz, L. (1998). Peroxide-scavenging deficit underlies oligodendrocyte susceptibility to oxidative stress. Glia 22, 371-378. doi: 10.1002/(SICI)1098-1136(199804)22:4<371::AID-GLIA6>3.0.CO;2-6

Kabel, A. M., Omar, M. S., Alhadhrami, A., Alharthi, S. S., and Alrobaian, M. M. (2018). Linagliptin potentiates the effect of 1-dopa on the behavioural, biochemical and immunohistochemical changes in experimentally-induced Parkinsonism: role of toll-like receptor 4, TGF-betal, NF-kappaB and glucagonlike peptide 1. Physiol. Behav. 188, 108-118. doi: 10.1016/j.physbeh.2018. 01.028

Kanninen, K., Malm, T. M., Jyrkkanen, H. K., Goldsteins, G., Keksa-Goldsteine, V., Tanila, H., et al. (2008). Nuclear factor erythroid 2-related factor 2 protects against beta amyloid. Mol. Cell. Neurosci. 39, 302-313. doi: 10.1016/j.mcn.2008. 07.010

Kappos, L., Radue, E. W., O’Connor, P., Polman, C., Hohlfeld, R., Calabresi, P., et al. (2010). A placebo-controlled trial of oral fingolimod in relapsing multiple sclerosis. N. Engl. J. Med. 362, 387-401. doi: 10.1056/NEJMoa0909494

Kennedy, B. P., Rao, F., Botiglieri, T., Sharma, S., Lillie, E. O., Ziegler, M. G., et al. (2005). Contributions of the sympathetic nervous system, glutathione, body mass and gender to blood pressure increase with normal aging: influence of heredity. J. Hum. Hypertens. 19, 951-969. doi: 10.1038/sj.jhh.1001912

Khan, S., Salloum, F., Das, A., Xi, L., Vetrovec, G. W., and Kukreja, R. C. (2006). Rapamycin confers preconditioning-like protection against ischemiareperfusion injury in isolated mouse heart and cardiomyocytes. J. Mol. Cell. Cardiol. 41, 256-264. doi: 10.1016/j.yjmcc.2006.04.014

Kim, S. K., and Novak, R. F. (2007). The role of intracellular signaling in insulinmediated regulation of drug metabolizing enzyme gene and protein expression. Pharmacol. Ther. 113, 88-120. doi: 10.1016/j.pharmthera.2006.07.004

Kim, T. S., Pae, C. U., Yoon, S. J., Jang, W. Y., Lee, N. J., Kim, J. J., et al. (2006). Decreased plasma antioxidants in patients with Alzheimer's disease. Int. J. Geriatr. Psychiatry 21, 344-348. doi: 10.1002/gps.1469

Kleinewietfeld, M., Manzel, A., Titze, J., Kvakan, H., Yosef, N., Linker, R. A., et al. (2013). Sodium chloride drives autoimmune disease by the induction of pathogenic TH17 cells. Nature 496, 518-522. doi: 10.1038/nature11868

Knight, E. M., Martins, I. V., Gumusgoz, S., Allan, S. M., and Lawrence, C. B. (2014). High-fat diet-induced memory impairment in triple-transgenic Alzheimer's disease ( $3 \mathrm{xTgAD})$ mice is independent of changes in amyloid and tau pathology. Neurobiol. Aging 35, 1821-1832. doi: 10.1016/j.neurobiolaging. 2014.02.010

Kobayashi, E. H., Suzuki, T., Funayama, R., Nagashima, T., Hayashi, M., Sekine, H., et al. (2016). Nrf2 suppresses macrophage inflammatory response by blocking proinflammatory cytokine transcription. Nat. Commun. 7:11624. doi: 10.1038/ ncomms 11624

Kwon, S. H., Ma, S. X., Hwang, J. Y., Lee, S. Y., and Jang, C. G. (2015). Involvement of the Nrf2/HO-1 signaling pathway in sulfuretin-induced protection against amyloid beta25-35 neurotoxicity. Neuroscience 304, 14-28. doi: 10.1016/j. neuroscience.2015.07.030

Langer-Gould, A., Brara, S. M., Beaber, B. E., and Koebnick, C. (2013). Childhood obesity and risk of pediatric multiple sclerosis and clinically isolated syndrome. Neurology 80, 548-552. doi: 10.1212/WNL.0b013e31828154f3

Lassmann, H. (2011). A dynamic view of the blood-brain barrier in active multiple sclerosis lesions. Ann. Neurol. 70, 1-2. doi: 10.1002/ana.22494

Lassmann, H. (2011). Pathophysiology of inflammation and tissue injury in multiple sclerosis: what are the targets for therapy. J. Neurol. Sci. 306, 167-169. doi: 10.1016/j.jns.2010.07.023

Lassmann, H. (2014). Mechanisms of white matter damage in multiple sclerosis. Glia 62, 1816-1830. doi: 10.1002/glia.22597
Lastres-Becker, I. (2017). Role of the transcription factor Nrf2 in Parkinson's disease: new insights. J. Alzheimers Dis. Parkinsonism 7:340.

Lastres-Becker, I., Garcia-Yague, A. J., Scannevin, R. H., Casarejos, M. J., Kugler, S., Rabano, A., et al. (2016). Repurposing the NRF2 activator dimethyl fumarate as therapy against synucleinopathy in Parkinson's disease. Antioxid. Redox Signal. 25, 61-77. doi: 10.1089/ars.2015.6549

Leakey, J. E., Cunny, H. C., Bazare, J., Webb, P. J., Feuers, R. J., Duffy, P. H., et al. (1989). Effects of aging and caloric restriction on hepatic drug metabolizing enzymes in the Fischer 344 rat. I: the cytochrome P-450 dependent monooxygenase system. Mech. Ageing Dev. 48, 145-155. doi: 10.1016/00476374(89)90046-8

Lee, J. M., Shih, A. Y., Murphy, T. H., and Johnson, J. A. (2003). NF-E2-related factor-2 mediates neuroprotection against mitochondrial complex I inhibitors and increased concentrations of intracellular calcium in primary cortical neurons. J. Biol. Chem. 278, 37948-37956. doi: 10.1074/jbc.M305204200

Li, L., Pan, H., Wang, H., Li, X., Bu, X., Wang, Q., et al. (2016). Interplay between VEGF and Nrf2 regulates angiogenesis due to intracranial venous hypertension. Sci. Rep. 6:37338. doi: 10.1038/srep37338

Li, H. H., Lin, S. L., Huang, C. N., Lu, F. J., Chiu, P. Y., Huang, W. N., et al. (2016). miR-302 attenuates amyloid-beta-induced neurotoxicity through activation of akt signaling. J. Alzheimers Dis. 50, 1083-1098. doi: 10.3233/JAD- 150741

Li, W., Prakash, R., Chawla, D., Du, W., Didion, S. P., Filosa, J. A., et al. (2013). Early effects of high-fat diet on neurovascular function and focal ischemic brain injury. Am. J. Physiol. Regul. Integr. Comp. Physiol. 304, R1001-R1008. doi: 10.1152/ajpregu.00523.2012

Licht-Mayer, S., Wimmer, I., Traffehn, S., Metz, I., Bruck, W., Bauer, J., et al. (2015). Cell type-specific Nrf2 expression in multiple sclerosis lesions. Acta Neuropathol. 130, 263-277. doi: 10.1007/s00401-015-1452-x

Lim, J. H., Kim, K. M., Kim, S. W., Hwang, O., and Choi, H. J. (2008). Bromocriptine activates NQO1 via Nrf2-PI3K/Akt signaling: novel cytoprotective mechanism against oxidative damage. Pharmacol. Res. 57, 325331. doi: 10.1016/j.phrs.2008.03.004

Lim, J. L., Wilhelmus, M. M., de Vries, H. E., Drukarch, B., Hoozemans, J. J., and van Horssen, J. (2014). Antioxidative defense mechanisms controlled by Nrf2: state-of-the-art and clinical perspectives in neurodegenerative diseases. Arch. Toxicol. 88, 1773-1786. doi: 10.1007/s00204-014-1338-z

Lin, A. L., Zheng, W., Halloran, J. J., Burbank, R. R., Hussong, S. A., Hart, M. J., et al. (2013). Chronic rapamycin restores brain vascular integrity and function through NO synthase activation and improves memory in symptomatic mice modeling Alzheimer's disease. J. Cereb. Blood Flow Metab. 33, 1412-1421. doi: $10.1038 / \mathrm{jcbfm} .2013 .82$

Lister, A., Nedjadi, T., Kitteringham, N. R., Campbell, F., Costello, E., Lloyd, B., et al. (2011). Nrf2 is overexpressed in pancreatic cancer: implications for cell proliferation and therapy. Mol. Cancer 10:37. doi: 10.1186/1476-459810-37

Liu, J. S., Zhao, M. L., Brosnan, C. F., and Lee, S. C. (2001). Expression of inducible nitric oxide synthase and nitrotyrosine in multiple sclerosis lesions. Am. J. Pathol. 158, 2057-2066. doi: 10.1016/S0002-9440(10)64677-9

Liu, Y., Deng, Y., Liu, H., Yin, C., Li, X., and Gong, Q. (2016). Hydrogen sulfide ameliorates learning memory impairment in APP/PS1 transgenic mice: a novel mechanism mediated by the activation of Nrf2. Pharmacol. Biochem. Behav. 150-151, 207-216. doi: 10.1016/j.pbb.2016.11.002

Logroscino, G., Marder, K., Cote, L., Tang, M. X., Shea, S., and Mayeux, R. (1996). Dietary lipids and antioxidants in Parkinson's disease: a population-based, case-control study. Ann. Neurol. 39, 89-94. doi: 10.1002/ana.410390113

Logsdon, A. F., Lucke-Wold, B. P., Rosen, C. L., and Huber, J. D. (2017). "Risk factors: aging," in Primer on Cerebrovascular Diseases, 2 Edn, eds L. R. Caplan, J. Biller, M. C. Leary, E. H. Lo, A. J. Thomas, M. Yenari, et al. (New York, NY: Elsevier), 162-167. doi: 10.1016/B978-0-12-803058-5.00033-3

Lopes, I. M., Forga, L., and Martinez, J. A. (2001). Effects of leptin resistance on acute fuel metabolism after a high carbohydrate load in lean and overweight young men. J. Am. Coll. Nutr. 20, 643-648. doi: 10.1080/07315724.2001. 10719162

Lu, T., Sun, X., Li, Y., Chai, Q., Wang, X. L., and Lee, H. C. (2017). Role of Nrf2 signaling in the regulation of vascular BK channel betal subunit expression and BK channel function in high-fat diet-induced diabetic mice. Diabetes 66, 2681-2690. doi: 10.2337/db17-0181 
Lublin, F. D., Reingold, S. C., Cohen, J. A., Cutter, G. R., Sorensen, P. S., Thompson, A. J., et al. (2014). Defining the clinical course of multiple sclerosis: the 2013 revisions. Neurology 83, 278-286. doi: 10.1212/WNL.0000000000000560

Ludtmann, M. H., Angelova, P. R., Zhang, Y., Abramov, A. Y., and DinkovaKostova, A. T. (2014). Nrf2 affects the efficiency of mitochondrial fatty acid oxidation. Biochem. J. 457, 415-424. doi: 10.1042/BJ20130863

MacKenzie, E. L., Ray, P. D., and Tsuji, Y. (2008). Role and regulation of ferritin H in rotenone-mediated mitochondrial oxidative stress. Free Radic. Biol. Med. 44, 1762-1771. doi: 10.1016/j.freeradbiomed.2008.01.031

Maffei, M., Halaas, J., Ravussin, E., Pratley, R. E., Lee, G. H., Zhang, Y., et al. (1995). Leptin levels in human and rodent: measurement of plasma leptin and ob RNA in obese and weight-reduced subjects. Nat. Med. 1, 1155-1161. doi: 10.1038/nm1195-1155

Manczak, M., Kandimalla, R., Yin, X., and Reddy, P. H. (2018). Hippocampal mutant APP and amyloid beta-induced cognitive decline, dendritic spine loss, defective autophagy, mitophagy and mitochondrial abnormalities in a mouse model of Alzheimer's disease. Hum. Mol. Genet. 27, 1332-1342. doi: 10.1093/ $\mathrm{hmg} / \mathrm{ddy} 042$

Mangialasche, F., Polidori, M. C., Monastero, R., Ercolani, S., Camarda, C., Cecchetti, R., et al. (2009). Biomarkers of oxidative and nitrosative damage in Alzheimer's disease and mild cognitive impairment. Ageing Res. Rev. 8, 285-305. doi: 10.1016/j.arr.2009.04.002

Marik, C., Felts, P. A., Bauer, J., Lassmann, H., and Smith, K. J. (2007). Lesion genesis in a subset of patients with multiple sclerosis: a role for innate immunity? Brain 130(Pt 11), 2800-2815. doi: 10.1093/brain/awm236

Martin, B., Golden, E., Carlson, O. D., Pistell, P., Zhou, J., Kim, W., et al. (2009). Exendin-4 improves glycemic control, ameliorates brain and pancreatic pathologies, and extends survival in a mouse model of Huntington's disease. Diabetes 58, 318-328. doi: 10.2337/db08-0799

Martin, B., Mattson, M. P., and Maudsley, S. (2006). Caloric restriction and intermittent fasting: two potential diets for successful brain aging. Ageing Res. Rev. 5, 332-353. doi: 10.1016/j.arr.2006.04.002

Martin-Montalvo, A., Villalba, J. M., Navas, P., and de Cabo, R. (2011). NRF2, cancer, and calorie restriction. Oncogene 30, 505-520. doi: 10.1038/onc 2010.492

Maswood, N., Young, J., Tilmont, E., Zhang, Z., Gash, D. M., Gerhardt, G. A., et al. (2004). Caloric restriction increases neurotrophic factor levels and attenuates neurochemical and behavioral deficits in a primate model of Parkinson's disease. Proc. Natl. Acad. Sci. U.S.A. 101, 18171-18176. doi: 10.1073/pnas. 0405831102

Matarese, G., Carrieri, P. B., La Cava, A., Perna, F., Sanna, V., De Rosa, V., et al. (2005). Leptin increase in multiple sclerosis associates with reduced number of CD4(+) CD25+ regulatory T cells. Proc. Natl. Acad. Sci. U.S.A. 102, 5150-5155. doi: $10.1073 /$ pnas. 0408995102

Matsuda, M., and Shimomura, I. (2013). Increased oxidative stress in obesity: implications for metabolic syndrome, diabetes, hypertension, dyslipidemia, atherosclerosis, and cancer. Obes. Res. Clin. Pract. 7, e330-e341. doi: 10.1016/j. orcp.2013.05.004

Mattson, M. P. (2012). Energy intake and exercise as determinants of brain health and vulnerability to injury and disease. Cell Metab. 16, 706-722. doi: 10.1016/j. cmet.2012.08.012

Mazon, J. N., de Mello, A. H., Ferreira, G. K., and Rezin, G. T. (2017). The impact of obesity on neurodegenerative diseases. Life Sci. 182, 22-28. doi: 10.1016/j.lfs. 2017.06.002

Mecocci, P., Boccardi, V., Cecchetti, R., Bastiani, P., Scamosci, M., Ruggiero, C., et al. (2018). A long journey into aging, brain aging, and Alzheimer's disease following the oxidative stress tracks. J. Alzheimers Dis. 62, 1319-1335. doi: 10.3233/JAD- 170732

Meydani, M., Das, S., Band, M., Epstein, S., and Roberts, S. (2011). The effect of caloric restriction and glycemic load on measures of oxidative stress and antioxidants in humans: results from the CALERIE Trial of Human Caloric Restriction. J. Nutr. Health Aging 15, 456-460. doi: 10.1007/s12603-011-0002-z

Meydani, S. N., Das, S. K., Pieper, C. F., Lewis, M. R., Klein, S., Dixit, V. D., et al. (2016). Long-term moderate calorie restriction inhibits inflammation without impairing cell-mediated immunity: a randomized controlled trial in non-obese humans. Aging 8, 1416-1431. doi: 10.18632/aging.100994

Michel, J. P. (2016). Is it possible to delay or prevent age-related cognitive decline? Korean J. Fam. Med. 37, 263-266. doi: 10.4082/kjfm.2016.37.5.263
Migliore, L., Fontana, I., Trippi, F., Colognato, R., Coppede, F., Tognoni, G., et al. (2005). Oxidative DNA damage in peripheral leukocytes of mild cognitive impairment and AD patients. Neurobiol. Aging 26, 567-573. doi: 10.1016/j. neurobiolaging.2004.07.016

Mitchell, J. R., Verweij, M., Brand, K., van de Ven, M., Goemaere, N., van den Engel, S., et al. (2010). Short-term dietary restriction and fasting precondition against ischemia reperfusion injury in mice. Aging Cell 9, 40-53. doi: 10.1111/j. 1474-9726.2009.00532.x

Morris, J. K., Bomhoff, G. L., Gorres, B. K., Davis, V. A., Kim, J., Lee, P. P., et al. (2011). Insulin resistance impairs nigrostriatal dopamine function. Exp. Neurol. 231, 171-180. doi: 10.1016/j.expneurol.2011.06.005

Morris, J. K., Bomhoff, G. L., Stanford, J. A., and Geiger, P. C. (2010). Neurodegeneration in an animal model of Parkinson's disease is exacerbated by a high-fat diet. Am. J. Physiol. Regul. Integr. Comp. Physiol. 299, R1082-R1090. doi: 10.1152/ajpregu.00449.2010

Morrison, C. D., Pistell, P. J., Ingram, D. K., Johnson, W. D., Liu, Y., FernandezKim, S. O., et al. (2010). High fat diet increases hippocampal oxidative stress and cognitive impairment in aged mice: implications for decreased Nrf2 signaling. J. Neurochem. 114, 1581-1589. doi: 10.1111/j.1471-4159.2010.06865.x

Munger, K. L., Chitnis, T., and Ascherio, A. (2009). Body size and risk of MS in two cohorts of US women. Neurology 73, 1543-1550. doi: 10.1212/WNL. 0b013e3181c0d6e0

Nakaso, K., Nakamura, C., Sato, H., Imamura, K., Takeshima, T., and Nakashima, K. (2006). Novel cytoprotective mechanism of anti-parkinsonian drug deprenyl: PI3K and Nrf2-derived induction of antioxidative proteins. Biochem. Biophys. Res. Commun. 339, 915-922. doi: 10.1016/j.bbrc.2005.11.095

Nguyen, T., Nioi, P., and Pickett, C. B. (2009). The Nrf2-antioxidant response element signaling pathway and its activation by oxidative stress. J. Biol. Chem. 284, 13291-13295. doi: 10.1074/jbc.R900010200

Niccoli, T., and Partridge, L. (2012). Ageing as a risk factor for disease. Curr. Biol. 22, R741-R752. doi: 10.1016/j.cub.2012.07.024

Nicholls, D. G. (2009). Spare respiratory capacity, oxidative stress and excitotoxicity. Biochem. Soc. Trans. 37(Pt 6), 1385-1388. doi: 10.1042/ BST0371385

Niso-Santano, M., Gonzalez-Polo, R. A., Bravo-San Pedro, J. M., GomezSanchez, R., Lastres-Becker, I., Ortiz-Ortiz, M. A., et al. (2010). Activation of apoptosis signal-regulating kinase 1 is a key factor in paraquat-induced cell death: modulation by the Nrf2/Trx axis. Free Radic. Biol. Med. 48, 1370-1381. doi: 10.1016/j.freeradbiomed.2010.02.024

Osmond, J. M., Mintz, J. D., and Stepp, D. W. (2010). Preventing increased blood pressure in the obese Zucker rat improves severity of stroke. Am. J. Physiol. Heart Circ. Physiol. 299, H55-H61. doi: 10.1152/ajpheart.01111.2009

Padurariu, M., Ciobica, A., Hritcu, L., Stoica, B., Bild, W., and Stefanescu, C. (2010). Changes of some oxidative stress markers in the serum of patients with mild cognitive impairment and Alzheimer's disease. Neurosci. Lett. 469, 6-10. doi: 10.1016/j.neulet.2009.11.033

Pandit, A., Vadnal, J., Houston, S., Freeman, E., and McDonough, J. (2009). Impaired regulation of electron transport chain subunit genes by nuclear respiratory factor 2 in multiple sclerosis. J. Neurol. Sci. 279, 14-20. doi: 10.1016/ j.jns.2009.01.009

Patel, M. (2016). Targeting oxidative stress in central nervous system disorders. Trends Pharm. Sci. 37, 768-778. doi: 10.1016/j.tips.2016.06.007

Patel, N. V., Gordon, M. N., Connor, K. E., Good, R. A., Engelman, R. W., Mason, J., et al. (2005). Caloric restriction attenuates Abeta-deposition in Alzheimer transgenic models. Neurobiol. Aging 26, 995-1000. doi: 10.1016/j. neurobiolaging.2004.09.014

Pearson, K. J., Lewis, K. N., Price, N. L., Chang, J. W., Perez, E., Cascajo, M. V., et al. (2008). Nrf2 mediates cancer protection but not prolongevity induced by caloric restriction. Proc. Natl. Acad. Sci. U.S.A. 105, 2325-2330. doi: 10.1073/ pnas.0712162105

Peng, W., Robertson, L., Gallinetti, J., Mejia, P., Vose, S., Charlip, A., et al. (2012). Surgical stress resistance induced by single amino acid deprivation requires Gcn2 in mice. Sci. Transl. Med. 4:118ra11. doi: 10.1126/scitranslmed.3002629

Perluigi, M., Sultana, R., Cenini, G., Di Domenico, F., Memo, M., Pierce, W. M., et al. (2009). Redox proteomics identification of 4-hydroxynonenal-modified brain proteins in Alzheimer's disease: role of lipid peroxidation in Alzheimer's disease pathogenesis. Proteomics Clin. Appl. 3, 682-693. doi: 10.1002/prca. 200800161 
Piccio, L., Stark, J. L., and Cross, A. H. (2008). Chronic calorie restriction attenuates experimental autoimmune encephalomyelitis. J. Leukoc. Biol. 84, 940-948. doi: 10.1189/jlb.0208133

Pipatpiboon, N., Pratchayasakul, W., Chattipakorn, N., and Chattipakorn, S. C. (2012). PPARgamma agonist improves neuronal insulin receptor function in hippocampus and brain mitochondria function in rats with insulin resistance induced by long term high-fat diets. Endocrinology 153, 329-338. doi: 10.1210/ en.2011-1502

Pistell, P. J., Morrison, C. D., Gupta, S., Knight, A. G., Keller, J. N., Ingram, D. K. et al. (2010). Cognitive impairment following high fat diet consumption is associated with brain inflammation. J. Neuroimmunol. 219, 25-32. doi: 10.1016/ j.jneuroim.2009.11.010

Procaccini, C., Santopaolo, M., Faicchia, D., Colamatteo, A., Formisano, L., de Candia, P., et al. (2016). Role of metabolism in neurodegenerative disorders. Metabolism 65, 1376-1390. doi: 10.1016/j.metabol.2016.05.018

Qin, W., Chachich, M., Lane, M., Roth, G., Bryant, M., de Cabo, R., et al. (2006). Calorie restriction attenuates Alzheimer's disease type brain amyloidosis in Squirrel monkeys (Saimiri sciureus). J. Alzheimers Dis. 10, 417-422. doi: 10. 3233/JAD-2006-10411

Qiu, G., Spangler, E. L., Wan, R., Miller, M., Mattson, M. P., So, K. F., et al. (2012). Neuroprotection provided by dietary restriction in rats is further enhanced by reducing glucocortocoids. Neurobiol. Aging 33, 2398-2410. doi: 10.1016/j. neurobiolaging.2011.11.025

Raina, A. K., Templeton, D. J., Deak, J. C., Perry, G., and Smith, M. A. (1999). Quinone reductase (NQO1), a sensitive redox indicator, is increased in Alzheimer's disease. Redox Rep. 4, 23-27. doi: 10.1179/13510009910153 4701

Ramsey, C. P., Glass, C. A., Montgomery, M. B., Lindl, K. A., Ritson, G. P., Chia, L. A., et al. (2007). Expression of $\mathrm{Nrf} 2$ in neurodegenerative diseases. J. Neuropathol. Exp. Neurol. 66, 75-85. doi: 10.1097/nen.0b013e31802d6da9

Rao, G., Xia, E., and Richardson, A. (1990). Effect of age on the expression of antioxidant enzymes in male Fischer F344 rats. Mech. Ageing Dev. 53, 49-60. doi: 10.1016/0047-6374(90)90033-C

Razay, G., Vreugdenhil, A., and Wilcock, G. (2006). Obesity, abdominal obesity and Alzheimer disease. Dement. Geriatr. Cogn. Disord. 22, 173-176. doi: 10. $1159 / 000094586$

Reed, T. T. (2011). Lipid peroxidation and neurodegenerative disease. Free Radic. Biol. Med. 51, 1302-1319. doi: 10.1016/j.freeradbiomed.2011.06.027

Rizzi, N., Brunialti, E., Cerri, S., Cermisoni, G., Levandis, G., Cesari, N., et al. (2018). In vivo imaging of early signs of dopaminergic neuronal death in an animal model of Parkinson's disease. Neurobiol. Dis. 114, 74-84. doi: 10.1016/j. nbd.2018.02.005

Roberge, M. C., Messier, C., Staines, W. A., and Plamondon, H. (2008). Food restriction induces long-lasting recovery of spatial memory deficits following global ischemia in delayed matching and non-matching-to-sample radial arm maze tasks. Neuroscience 156, 11-29. doi: 10.1016/j.neuroscience.2008. 05.062

Safdar, A., deBeer, J., and Tarnopolsky, M. A. (2010). Dysfunctional Nrf2-Keap1 redox signaling in skeletal muscle of the sedentary old. Free Radic. Biol. Med. 49, 1487-1493. doi: 10.1016/j.freeradbiomed.2010.08.010

Sah, S. K., Lee, C., Jang, J. H., and Park, G. H. (2017). Effect of high-fat diet on cognitive impairment in triple-transgenic mice model of Alzheimer's disease. Biochem. Biophys. Res. Commun. 493, 731-736. doi: 10.1016/j.bbrc.2017.08.122

Saleh, M. C., Connell, B. J., and Saleh, T. M. (2010). Resveratrol preconditioning induces cellular stress proteins and is mediated via NMDA and estrogen receptors. Neuroscience 166, 445-454. doi: 10.1016/j.neuroscience.2009. 12.060

Samiec, P. S., Drews-Botsch, C., Flagg, E. W., Kurtz, J. C., Sternberg, P., Reed, R. L., et al. (1998). Glutathione in human plasma: decline in association with aging, age-related macular degeneration, and diabetes. Free Radic. Biol. Med. 24, 699-704. doi: 10.1016/S0891-5849(97)00286-4

Sandberg, M., Patil, J., D’Angelo, B., Weber, S. G., and Mallard, C. (2014). NRF2regulation in brain health and disease: implication of cerebral inflammation. Neuropharmacology 79, 298-306. doi: 10.1016/j.neuropharm.2013.11.004

Satoh, T., Harada, N., Hosoya, T., Tohyama, K., Yamamoto, M., and Itoh, K. (2009). Keap1/Nrf2 system regulates neuronal survival as revealed through study of keap1 gene-knockout mice. Biochem. Biophys. Res. Commun. 380, 298-302. doi: 10.1016/j.bbrc.2009.01.063
Satoh, T., Okamoto, S. I., Cui, J., Watanabe, Y., Furuta, K., Suzuki, M., et al. (2006). Activation of the Keap1/Nrf2 pathway for neuroprotection by electrophilic [correction of electrophillic] phase II inducers. Proc. Natl. Acad. Sci. U.S.A. 103, 768-773. doi: 10.1073/pnas.0505723102

Schernhammer, E., Hansen, J., Rugbjerg, K., Wermuth, L., and Ritz, B. (2011). Diabetes and the risk of developing Parkinson's disease in Denmark. Diabetes Care 34, 1102-1108. doi: 10.2337/dc10-1333

Schreibelt, G., Musters, R. J., Reijerkerk, A., de Groot, L. R., van der Pol, S. M., Hendrikx, E. M., et al. (2006). Lipoic acid affects cellular migration into the central nervous system and stabilizes blood-brain barrier integrity. J. Immunol. 177, 2630-2637. doi: 10.4049/jimmunol.177.4.2630

Schwarz, S., and Leweling, H. (2005). Multiple sclerosis and nutrition. Mult. Scler. 11, 24-32. doi: 10.1191/1352458505ms1119oa

Selkoe, D. J. (1994). Alzheimer's disease: a central role for amyloid. J. Neuropathol. Exp. Neurol. 53, 438-447. doi: 10.1097/00005072-19940900000003

Senanayake, V. K., Jin, W., Mochizuki, A., Chitou, B., and Goodenowe, D. B. (2015). Metabolic dysfunctions in multiple sclerosis: implications as to causation, early detection, and treatment, a case control study. BMC Neurol. 15:154. doi: 10.1186/s12883-015-0411-4

Sepcic, J., Mesaros, E., Materljan, E., and Sepic-Grahovac, D. (1993). Nutritional factors and multiple sclerosis in Gorski Kotar, Croatia. Neuroepidemiology 12, 234-240. doi: 10.1159/000110322

Shah, Z. A., Li, R. C., Thimmulappa, R. K., Kensler, T. W., Yamamoto, M., Biswal, S., et al. (2007). Role of reactive oxygen species in modulation of Nrf2 following ischemic reperfusion injury. Neuroscience 147, 53-59. doi: 10.1016/j. neuroscience.2007.02.066

Shih, A. Y., Li, P., and Murphy, T. H. (2005). A small-molecule-inducible Nrf2mediated antioxidant response provides effective prophylaxis against cerebral ischemia in vivo. J. Neurosci. 25, 10321-10335. doi: 10.1523/JNEUROSCI.401405.2005

Shih, P. H., and Yen, G. C. (2007). Differential expressions of antioxidant status in aging rats: the role of transcriptional factor Nrf2 and MAPK signaling pathway. Biogerontology 8, 71-80. doi: 10.1007/s10522-006-9033-y

Shin, S., Wakabayashi, J., Yates, M. S., Wakabayashi, N., Dolan, P. M., Aja, S., et al. (2009). Role of Nrf2 in prevention of high-fat diet-induced obesity by synthetic triterpenoid CDDO-imidazolide. Eur. J. Pharmacol. 620, 138-144. doi: 10.1016/j.ejphar.2009.08.022

Simmons, S. B., Pierson, E. R., Lee, S. Y., and Goverman, J. M. (2013). Modeling the heterogeneity of multiple sclerosis in animals. Trends Immunol. 34, 410-422. doi: 10.1016/j.it.2013.04.006

Son, T. G., Camandola, S., Arumugam, T. V., Cutler, R. G., Telljohann, R. S., Mughal, M. R., et al. (2010). Plumbagin, a novel Nrf2/ARE activator, protects against cerebral ischemia. J. Neurochem. 112, 1316-1326. doi: 10.1111/j.14714159.2009.06552.x

Sporn, M. B., and Liby, K. T. (2012). NRF2 and cancer: the good, the bad and the importance of context. Nat. Rev. Cancer 12, 564-571. doi: 10.1038/ $\operatorname{nrc} 3278$

Stanek, K. M., Grieve, S. M., Brickman, A. M., Korgaonkar, M. S., Paul, R. H., Cohen, R. A., et al. (2011). Obesity is associated with reduced white matter integrity in otherwise healthy adults. Obesity 19, 500-504. doi: 10.1038/oby. 2010.312

Strong, K., Mathers, C., and Bonita, R. (2007). Preventing stroke: saving lives around the world. Lancet Neurol. 6, 182-187. doi: 10.1016/S1474-4422(07) 70031-5

Suh, J. H., Shenvi, S. V., Dixon, B. M., Liu, H., Jaiswal, A. K., Liu, R. M., et al. (2004). Decline in transcriptional activity of Nrf2 causes age-related loss of glutathione synthesis, which is reversible with lipoic acid. Proc. Natl. Acad. Sci. U.S.A. 101, 3381-3386. doi: 10.1073/pnas.0400282101

Sun, Y., Yang, T., Leak, R. K., Chen, J., and Zhang, F. (2017). Preventive and protective roles of dietary Nrf2 activators against central nervous system diseases. CNS Neurol. Disord. Drug Targets 16, 326-338. doi: 10.2174/ 1871527316666170102120211

Takeda, S., Sato, N., Uchio-Yamada, K., Sawada, K., Kunieda, T., Takeuchi, D., et al. (2010). Diabetes-accelerated memory dysfunction via cerebrovascular inflammation and Abeta deposition in an Alzheimer mouse model with diabetes. Proc. Natl. Acad. Sci. U.S.A. 107, 7036-7041. doi: 10.1073/pnas. 1000645107 
Talbot, K., Wang, H. Y., Kazi, H., Han, L. Y., Bakshi, K. P., Stucky, A., et al. (2012). Demonstrated brain insulin resistance in Alzheimer's disease patients is associated with IGF-1 resistance, IRS-1 dysregulation, and cognitive decline. J. Clin. Investig. 122, 1316-1338. doi: 10.1172/JCI59903

Tanigawa, S., Fujii, M., and Hou, D. X. (2007). Action of Nrf2 and keap1 in AREmediated NQO1 expression by quercetin. Free Radic. Biol. Med. 42, 1690-1703. doi: 10.1016/j.freeradbiomed.2007.02.017

Tanito, M., Agbaga, M. P., and Anderson, R. E. (2007). Upregulation of thioredoxin system via Nrf2-antioxidant responsive element pathway in adaptive-retinal neuroprotection in vivo and in vitro. Free Radic. Biol. Med. 42, 1838-1850. doi: 10.1016/j.freeradbiomed.2007.03.018

Tanji, K., Maruyama, A., Odagiri, S., Mori, F., Itoh, K., Kakita, A., et al. (2013). Keap1 is localized in neuronal and glial cytoplasmic inclusions in various neurodegenerative diseases. J. Neuropathol. Exp. Neurol. 72, 18-28. doi: 10. 1097/NEN.0b013e31827b5713

Tarantini, S., Valcarcel-Ares, M. N., Yabluchanskiy, A., Tucsek, Z., Hertelendy, P., Kiss, T., et al. (2018). Nrf2 deficiency exacerbates obesity-induced oxidative stress, neurovascular dysfunction, blood-brain barrier disruption, neuroinflammation, amyloidogenic gene expression, and cognitive decline in mice, mimicking the aging phenotype. J. Gerontol. Ser. A Biol. Sci. Med. Sci. 73, 853-863. doi: 10.1093/gerona/glx177

Tebay, L. E., Robertson, H., Durant, S. T., Vitale, S. R., Penning, T. M., Dinkova-Kostova, A. T., et al. (2015). Mechanisms of activation of the transcription factor Nrf2 by redox stressors, nutrient cues, and energy status and the pathways through which it attenuates degenerative disease. Free Radic. Biol. Med. 88(Pt B), 108-146. doi: 10.1016/j.freeradbiomed.2015. 06.021

Thompson, A. J. (2008). Multiple sclerosis-a global disorder and still poorly managed. Lancet Neurol. 7, 1078-1079. doi: 10.1016/S1474-4422(08) 70246-1

Tola, M. R., Granieri, E., Malagu, S., Caniatti, L., Casetta, I., Govoni, V., et al. (1994). Dietary habits and multiple sclerosis. A retrospective study in Ferrara, Italy. Acta Neurol. 16, 189-197.

Tucsek, Z., Toth, P., Sosnowska, D., Gautam, T., Mitschelen, M., Koller, A., et al. (2014). Obesity in aging exacerbates blood-brain barrier disruption, neuroinflammation, and oxidative stress in the mouse hippocampus: effects on expression of genes involved in beta-amyloid generation and Alzheimer's disease. J. Gerontol. Ser. A Biol. Sci. Med. Sci. 69, 1212-1226. doi: 10.1093/ gerona/glt177

Tufekci, K. U., Civi Bayin, E., Genc, S., and Genc, K. (2011). The Nrf2/ARE pathway: a promising target to counteract mitochondrial dysfunction in Parkinson's disease. Parkinsons Dis. 2011:314082. doi: 10.4061/2011/31 4082

Tzima, S., Victoratos, P., Kranidioti, K., Alexiou, M., and Kollias, G. (2009). Myeloid heme oxygenase-1 regulates innate immunity and autoimmunity by modulating IFN-beta production. J. Exp. Med. 206, 1167-1179. doi: 10.1084/ jem. 20081582

Ungvari, Z., Bailey-Downs, L., Gautam, T., Jimenez, R., Losonczy, G., Zhang, C., et al. (2011a). Adaptive induction of NF-E2-related factor-2-driven antioxidant genes in endothelial cells in response to hyperglycemia. Am. J. Physiol. Heart Circ. Physiol. 300, H1133-H1140. doi: 10.1152/ajpheart.00402. 2010

Ungvari, Z., Bailey-Downs, L., Sosnowska, D., Gautam, T., Koncz, P., Losonczy, G., et al. (2011b). Vascular oxidative stress in aging: a homeostatic failure due to dysregulation of NRF2-mediated antioxidant response. Am. J. Physiol. Heart Circ. Physiol. 301, H363-H372. doi: 10.1152/ajpheart.01134. 2010

Ungvari, Z., Bailey-Downs, L., Gautam, T., Sosnowska, D., Wang, M., Monticone, R. E., et al. (2011c). Age-associated vascular oxidative stress, Nrf2 dysfunction, and NF-\{kappa\}B activation in the nonhuman primate Macaca mulatta. J. Gerontol. Ser. A Biol. Sci. Med. Sci. 66, 866-875. doi: 10.1093/gerona/ glr092

Uttara, B., Singh, A. V., Zamboni, P., and Mahajan, R. T. (2009). Oxidative stress and neurodegenerative diseases: a review of upstream and downstream antioxidant therapeutic options. Curr. Neuropharmacol. 7, 65-74. doi: 10.2174/ 157015909787602823

Van der Goes, A., Wouters, D., Van Der Pol, S. M., Huizinga, R., Ronken, E., Adamson, P., et al. (2001). Reactive oxygen species enhance the migration of monocytes across the blood-brain barrier in vitro. FASEB J. 15, 1852-1854. doi: 10.1096/fj.00-0881fje

Vasconcelos, A. R., Orellana, A. M. M., Paixão, A. G., Scavone, C., and Kawamoto, E. M. (2018). "Intermittent fasting and caloric restriction: neuroplasticity and neurodegeneration," in Handbook of Famine, Starvation, and Nutrient Deprivation, eds V. Preedy and V. Patel (Cham: Springer).

Vazquez-Medina, J. P., Zenteno-Savin, T., Forman, H. J., Crocker, D. E., and Ortiz, R. M. (2011). Prolonged fasting increases glutathione biosynthesis in postweaned northern elephant seals. J. Exp. Biol. 214(Pt 8), 1294-1299. doi: 10.1242/jeb.054320

Verweij, M., van Ginhoven, T. M., Mitchell, J. R., Sluiter, W., van den Engel, S., Roest, H. P., et al. (2011). Preoperative fasting protects mice against hepatic ischemia/reperfusion injury: mechanisms and effects on liver regeneration. Liver Transpl. 17, 695-704. doi: 10.1002/lt.22243

Wakabayashi, N., Itoh, K., Wakabayashi, J., Motohashi, H., Noda, S., Takahashi, S., et al. (2003). Keap1-null mutation leads to postnatal lethality due to constitutive Nrf2 activation. Nat. Genet. 35, 238-245. doi: 10.1038/ ng1248

Wang, J., Ho, L., Qin, W., Rocher, A. B., Seror, I., Humala, N., et al. (2005). Caloric restriction attenuates beta-amyloid neuropathology in a mouse model of Alzheimer's disease. FASEB J. 19, 659-661. doi: 10.1096/fj.04-31 82 fje

Wang, X., Svedin, P., Nie, C., Lapatto, R., Zhu, C., Gustavsson, M., et al. (2007). N-acetylcysteine reduces lipopolysaccharide-sensitized hypoxicischemic brain injury. Ann. Neurol. 61, 263-271. doi: 10.1002/ana. 21066

Wang, Y., Miao, Y., Mir, A. Z., Cheng, L., Wang, L., Zhao, L., et al. (2016). Inhibition of beta-amyloid-induced neurotoxicity by pinocembrin through Nrf2/HO-1 pathway in SH-SY5Y cells. J. Neurol. Sci. 368, 223-230. doi: 10.1016/ j.jns.2016.07.010

Willeumier, K. C., Taylor, D. V., and Amen, D. G. (2011). Elevated BMI is associated with decreased blood flow in the prefrontal cortex using SPECT imaging in healthy adults. Obesity 19, 1095-1097. doi: 10.1038/oby. 2011.16

Winer, S., Paltser, G., Chan, Y., Tsui, H., Engleman, E., Winer, D., et al. (2009). Obesity predisposes to Th17 bias. Eur. J. Immunol. 39, 2629-2635. doi: 10.1002/ eji.200838893

Witte, M. E., Mahad, D. J., Lassmann, H., and van Horssen, J. (2014). Mitochondrial dysfunction contributes to neurodegeneration in multiple sclerosis. Trends Mol. Med. 20, 179-187. doi: 10.1016/j.molmed.2013.11.007

World Health Organization [WHO] (2011). World Health Statistics. Geneva: WHO, 162.

Wruck, C. J., Claussen, M., Fuhrmann, G., Romer, L., Schulz, A., Pufe, T., et al. (2007). Luteolin protects rat PC12 and C6 cells against MPP+ induced toxicity via an ERK dependent Keap1-Nrf2-ARE pathway. J. Neural Transm. Suppl. 72, 57-67. doi: 10.1007/978-3-211-73574-9_9

Xu, Q., Park, Y., Huang, X., Hollenbeck, A., Blair, A., Schatzkin, A., et al. (2011). Diabetes and risk of Parkinson's disease. Diabetes Care 34, 910-915. doi: 10. 2337/dc10-1922

Xu, X., Zhang, L., Ye, X., Hao, Q., Zhang, T., Cui, G., et al. (2018). Nrf2/ARE pathway inhibits ROS-induced NLRP3 inflammasome activation in BV2 cells after cerebral ischemia reperfusion. Inflamm. Res. 67, 57-65. doi: 10.1007/ s00011-017-1095-6

Yang, T., Sun, Y., Mao, L., Zhang, M., Li, Q., Zhang, L., et al. (2018). Brain ischemic preconditioning protects against ischemic injury and preserves the blood-brain barrier via oxidative signaling and Nrf2 activation. Redox Biol. 17, 323-337. doi: 10.1016/j.redox.2018.05.001

Zagorski, J. W., Turley, A. E., Freeborn, R. A., VanDenBerg, K. R., Dover, H. E., Kardell, B. R., et al. (2018). Differential effects of the Nrf2 activators tBHQ and CDDO-Im on the early events of T cell activation. Biochem. Pharm. 147, 67-76. doi: 10.1016/j.bcp.2017.11.005

Zhang, P., Singh, A., Yegnasubramanian, S., Esopi, D., Kombairaju, P., Bodas, M., et al. (2010). Loss of Kelch-like ECH-associated protein 1 function in prostate cancer cells causes chemoresistance and radioresistance and promotes tumor growth. Mol. Cancer Ther. 9, 336-346. doi: 10.1158/1535-7163.MCT-090589

Zhu, H., Itoh, K., Yamamoto, M., Zweier, J. L., and Li, Y. (2005). Role of Nrf2 signaling in regulation of antioxidants and phase 2 enzymes in 
cardiac fibroblasts: protection against reactive oxygen and nitrogen speciesinduced cell injury. FEBS Lett. 579, 3029-3036. doi: 10.1016/j.febslet.2005. 04.058

Zlokovic, B. V. (2011). Neurovascular pathways to neurodegeneration in Alzheimer's disease and other disorders. Nat. Rev. Neurosci. 12, 723-738. doi: $10.1038 / \mathrm{nrn} 3114$

Zou, Y., Hong, B., Fan, L., Zhou, L., Liu, Y., Wu, Q., et al. (2013). Protective effect of puerarin against beta-amyloid-induced oxidative stress in neuronal cultures from rat hippocampus: involvement of the GSK-3beta/Nrf2 signaling pathway. Free Radic. Res. 47, 55-63. doi: 10.3109/10715762.2012.74 2518
Conflict of Interest Statement: The authors declare that the research was conducted in the absence of any commercial or financial relationships that could be construed as a potential conflict of interest.

Copyright $\odot 2019$ Vasconcelos, dos Santos, Scavone and Munhoz. This is an openaccess article distributed under the terms of the Creative Commons Attribution License (CC BY). The use, distribution or reproduction in other forums is permitted, provided the original author(s) and the copyright owner(s) are credited and that the original publication in this journal is cited, in accordance with accepted academic practice. No use, distribution or reproduction is permitted which does not comply with these terms. 